\title{
Seasonal Asset Allocation: Evidence from Mutual Fund Flows
}

\author{
Mark J. Kamstra, Lisa A. Kramer, Maurice D. Levi, and \\ Russ Wermers*
}

\begin{abstract}
We analyze the flow of money between mutual fund categories, finding strong evidence of seasonality in investor risk aversion. Aggregate investor flow data reveal an investor preference for safe mutual funds in autumn and risky funds in spring. During September alone, outflows from equity funds average $\$ 13$ billion, controlling for previously documented flow determinants (e.g., capital-gains overhang). This movement of large amounts of money between fund categories is correlated with seasonality in investor risk aversion, consistent with investors preferring safer (riskier) investments in autumn (spring). We find consistent evidence in Canada and also in Australia, where seasons are offset by 6 months.
\end{abstract}

\section{Introduction}

Recent studies find that environmental factors can influence a particular aspect of investor sentiment: willingness to take financial risk. See, for instance,

*Kamstra (corresponding author), mkamstra@schulich.yorku.ca, Schulich School of Business, York University; Kramer, 1kramer@rotman.utoronto.ca, University of Toronto; Levi, maurice .levi@sauder.ubc.ca, Sauder School of Business, UBC; Wermers, rwermers@ rhsmith.umd.edu, Smith School of Business, University of Maryland. We are grateful to an anonymous referee for helpful comments. We have benefited from valuable conversations with Devraj Basu, Hendrik Bessembinder (the editor), Michael Brennan, Raymond da Silva Rosa, Kent Daniel, Ramon DeGennaro, Darren Duxbury, Roger Edelen, Zekeriya Eser, Henry Fenig, Mark Fisher, Kenneth Froot, Luis Goncalves-Pinto, Rob Heinkel, Woodrow Johnson, Alan Kraus, David Laibson, Josef Lakonishok, Dong Lou, José Vincente Martinez, Vasant Naik, Sergei Polevikov, Veronika Pool, Jacob Sagi, Rudi Schadt, Kelly Shue, Neal Stoughton, Rodney Sullivan, Ellis Tallman, Geoffrey Tate, Robin Thurston, Paula Tkac, William Zame, and seminar and conference participants at ASU, CUHK, the Federal Reserve Bank of Atlanta, George Mason University, Maastricht University, Peking University, Queen's University, UBC, the University of Guelph, UNC at Chapel Hill, the University of Utah, Western University, the 3L Finance Workshop at the National Bank of Belgium, the 2011 Academy of Behavioral Finance and Economics Conference, the 2014 AFA meetings, the 2012 Australasian Finance and Banking Conference, the 2003 CIRANO Fund Management Conference, the 2012 EFA meetings, the 2011 FIRS, the 2010 Household Heterogeneity and Household Finance Conference, the 2011 IIEP/IMF Advances in Behavioral Finance Conference, the 2014 Mitsui Finance Conference at the University of Michigan, the 2013 NBER Behavioral Economics Conference, the 2014 QMUL Behavioural Finance Working Group Conference, and the 2004 Wharton Mutual Funds Conference. We thank the Investment Company Institute, the Investment Funds Institute of Canada, and Morningstar for generously providing much of the data used in this study and Sean Collins and Sukanya Srichandra for help in interpreting the U.S. and Canadian data, respectively. Kamstra, Kramer, and Levi gratefully acknowledge the financial support of the Social Sciences and Humanities Research Council of Canada. Kramer additionally thanks the Canadian Securities Institute Research Foundation for generous financial support. Any remaining errors are our own. 
Malmendier and Nagel (2011), Guiso, Sapienza, and Zingales (2013), and Bassi, Colacito, and Fulghieri (2013). Another body of work shows that changes in the mood or sentiment of large groups of individuals may affect mutual fund flows between different asset classes. See Indro (2004) and Ben-Rephael, Kandel, and Wohl (2011), (2012).

We seek to understand the role that investor sentiment, in general, and timevarying risk aversion, in particular, play in determining flows to mutual funds of different risk classes. Our findings have the potential to inform economists and policymakers about the role of behavioral factors in shaping flows to and from mutual funds. In turn, developing a deeper understanding of the role of changing investor preferences in driving flows among different mutual fund asset classes may improve our understanding of how investor sentiment contributes to seasonality in asset-class returns.

Specifically, we document a heretofore unknown and strong seasonality in mutual fund flows to and exchanges between fund asset categories. We show that flows to and exchanges between fund categories (e.g., equity versus money market), controlling for known influences, are strongly dependent on the season and interact with the relative riskiness of the categories. Households, in aggregate, move money into relatively safe fund categories during the fall and into riskier fund categories during the spring. Further, we find strong evidence that this seasonality is correlated with the timing of seasonal variation in risk aversion. Specifically, this seasonal variation in fund flows across risk categories is consistent with findings from the medical literature that individuals are influenced by strong seasonal factors that tend to synchronize their mood across the population (see Harmatz, Well, Overtree, Kawamura, Rosal, and Ockene (2000)) and with Kramer and Weber's (2012) finding that individuals are, on average, significantly more financially risk averse in the fall/winter than in the spring/summer.

Prior studies have documented financial-market evidence consistent with seasonality in risk aversion by concentrating on returns. ${ }^{1}$ In contrast, we provide new evidence on seasonal risk-aversion-driven investing behavior that is based directly on quantities of funds chosen by investors at a fixed price (the daily closing mutual fund net asset value (NAV)). We believe that an examination of the trades of mutual fund shares represents a unique setting to study sentiment related to degree of risk aversion because large quantities of shares may be purchased at that day's NAV. Investor choice of quantities at a fixed price is more direct evidence than prior studies based on seasonality in asset-class returns because prices in most other markets adjust to temporary supply-versus-demand conditions, making the reason for buying or selling difficult to determine. The patterns of mutual fund flows and net exchanges provide the first direct evidence that some

\footnotetext{
${ }^{1}$ For example, Kamstra, Kramer, and Levi (2003), (2015) and Garrett, Kamstra, and Kramer (2005) document seasonal patterns in returns to publicly traded stocks and bonds consistent with seasonally varying household risk preferences, even when controlling for other known seasonal influences on returns, such as year-end tax effects. Furthermore, Kamstra, Kramer, Levi, and Wang (2014) examine an asset pricing model with a representative agent who experiences seasonally varying risk preferences. They find that plausible values of risk-preference parameters are capable of generating the empirically observed seasonal patterns in equity and Treasury returns.
} 
individual investors exhibit marked seasonal changes in sentiment related to risk aversion.

We study mutual fund flows and exchanges because they are largely the outcome of individual investor decisions. According to the Investment Company Institute (2014), 46\% of all U.S. households owned mutual funds during 2013. Individuals held $90 \%$ of total mutual fund assets, with the remainder held by institutional investors. ${ }^{2}$ The implication is that mutual fund flows predominantly reflect the sentiment of individual investors, and a broad cross section of individuals is involved in mutual fund markets. Thus, if seasonally varying risk aversion influences the investment decisions of some individuals, it is reasonable to expect that the effects would be apparent in mutual fund flows and exchanges because there is no mechanism for arbitrageurs to directly counter the trades of such individuals (i.e., open-end mutual fund shares cannot be sold short). Overall, mutual fund flows and exchanges uniquely represent the decisions of buyers, or sellers, without the confounding influence of the counterparty to the trade (unlike stock trades, for instance).

The U.S. data we employ are monthly flows to 30 mutual fund categories during 1985-2006, which we use to build five risk classes of funds: equity, hybrid, corporate fixed income, government fixed income, and money market. We also use data on net exchanges (i.e., within fund-family transfers of money) between asset classes, which are affected much less by the liquidity needs of households (e.g., year-end bonuses or tax-season spikes in contributions) and thus add a clearer view of the sentiment-driven trades of retail investors. We investigate monthly flows and exchanges with a model that controls for previously documented influences on flows, including return chasing, capital-gains overhang, recent advertising, and liquidity needs (we employ personal savings rates). ${ }^{3}$ We also explore models that explicitly control for autocorrelation in flows (because flows and exchanges are slowly mean-reverting) and models with dummy variables that allow for arbitrary flow movement around the tax year-end.

With the U.S. flow and exchange data, we find empirical results that are strongly consistent with an influential seasonal effect on individual investor risk taking. Specifically, after controlling for other influences on flows, some of which are seasonal, we find that the magnitude of outflows from equity funds explained by seasonal risk aversion during the fall month of September (circa 2006) is approximately $\$ 13$ billion, and the increase in flows into money market funds is approximately $\$ 3$ billion. The direction of flows then reverses in the spring. ${ }^{4}$

\footnotetext{
${ }^{2}$ We qualify this statement by noting that the proportion held by institutional investors is much higher in money market funds relative to other asset classes. For this reason, we report robustness checks based on retail-share-class-only data.

${ }^{3}$ Bergstresser and Poterba (2002) and Johnson and Poterba (2008) show net flows to funds with large future capital-gains distributions are significantly lower than net flows to other funds. Jain and Wu (2000), Gallaher, Kaniel, and Starks (2006), and Aydogdu and Wellman (2011) show investors react to fund advertising. Ippolito (1992) and Sirri and Tufano (1998) show investors return chase.

${ }^{4}$ To make up the difference between the inflows and outflows, we believe that investors likely find other substitutes for safe money market funds, such as interest-bearing checking accounts. As we show later in the paper, we find support for this view when we consider seasonalities in bank account inflows and outflows.
} 
When we examine net exchanges, we find evidence of seasonality in investor sentiment consistent with the net flow data, although it is smaller in magnitude.

As an out-of-sample test, we examine Canadian mutual fund data for 10 fund classes, which we use to build four different risk classes of funds: equity, hybrid, fixed income, and global fixed income. This provides us with a similar but more northerly financial market compared with the United States. Medical evidence shows that seasonal variation in mood is more extreme at higher latitudes (see, e.g., Magnusson (2000) and Rosenthal, Sack, Gillin, Lewy, Goodwin, Davenport, Mueller, Newsome, and Wehr (1984)). Thus, if the seasonally varying risk-aversion hypothesis is correct, we should see more exaggerated seasonal exchanges in Canada than we see in the United States. Indeed, we find that seasonal net exchanges into and out of equity, hybrid, and safe fund classes show roughly double the proportional flows in Canada relative to the United States, consistent with the seasonally varying risk-aversion hypothesis.

As a second out-of-sample test, we examine flow data from Australia, where the seasons are 6 months out of phase relative to the United States and Canada, and the population lies closer to the equator and should therefore be less affected by seasonal variation in mood. If the seasonally varying risk-aversion hypothesis is correct, these flows should show a seasonal cycle that is 6 months out of phase relative to seasonality in northern hemisphere markets, and we should see attenuated seasonal flows relative to the United States. This is exactly what we find.

We show in online appendices that our findings are robust to a number of robustness checks, including the use of the Center for Research in Security Prices (CRSP) U.S. mutual fund database to compute estimated flows (to use in place of the flows data from the Investment Company Institute (ICI)), consideration of various subsample time periods, use of retail-share-class-only flows (instead of retail and institutional share class flows collectively), various alterations to the econometric specification (e.g., as estimation method, inclusion/exclusion of monthly dummy variables, inclusion/exclusion of sufficient lags of the dependent variable to control for autocorrelation, and so forth), use of different proxies to capture performance chasing, and use of different methods to control for capital-gains overhang. In all cases, the relation between seasonal risk aversion and mutual fund flows to different asset classes remains economically and statistically significant. We also consider partitioning the flows data into high versus low periods conditional on, variously, contemporaneous equity returns, contemporaneous equity fund capital gains, mutual fund sales, and mutual fund redemptions. Conditioning the data in these ways provides an alternate means of testing the possibility that flows are driven by seasonality in crisis-driven flight-to-quality behavior or seasonality in the availability of or need for liquidity, rather than seasonality in risk aversion. We find very similar seasonal patterns in flows across all of these high/low partitions of the data, lending further support to the notion that seasonality in factors such as returns, capital gains, fund sales, and so forth do not produce the seasonality in flows that we study.

The structure of the paper is as follows: In Section II, we describe how seasonally changing risk aversion can translate into an economically significant influence on an individual's choice of assets. In Section III, we define measures to 
capture the impact of seasonally changing risk aversion on investment decisions. We introduce the U.S. flows data and other variables in Section IV, and we present findings in Section V. In Section VI, we present findings based on Canadian and Australian flows. We summarize extensive robustness checks in Section VII. Section VIII concludes.

\section{The Link between Seasons and Risk Taking}

The hypothesized link between seasons and investment choices is based on two elements. First, the seasonal reduction in daylight that occurs during the fall each year tends to lead to a marked deterioration in people's moods as a direct consequence of the reduced hours of daylight. People who experience extreme changes of this variety are labeled by the medical profession as suffering from seasonal depression, formally known as seasonal affective disorder (SAD). Even healthy people (i.e., people not suffering from SAD) experience milder but still problematic mood changes, commonly called "winter blues." Second, winter blues and SAD are associated with increased risk aversion, including financial risk aversion. Both of these connections are based on behavioral and biochemical evidence. Further, they have been extensively studied in clinical and experimental investigations.

Much research, including that of Molin, Mellerup, Bolwig, Scheike, and Dam (1996) and Young, Meaden, Fogg, Cherin, and Eastman (1997), supports the first element of the link between seasons and risk aversion, namely, the causal connection between reduced hours of daylight and the onset of mild or severe seasonal depression. Medical evidence demonstrates that as the number of hours of daylight drops in the fall, up to $10 \%$ of the population suffers from very severe clinical depression, or SAD. ${ }^{5}$ Terman (1988) and Kasper, Wehr, Bartko, Gaist, and Rosenthal (1989) find that a quarter or more of the general population experiences seasonal changes in mood sufficient to pose a problem in their lives, and more recent evidence suggests that individuals lie along a continuum in terms of their susceptibility to seasonal depression, with even healthy individuals (i.e., those who do not suffer from severe seasonal depression) experiencing observable seasonal variation in their mood. For instance, Kramer and Weber (2012) study a panel of hundreds of people and find that both healthy and depressed individuals are significantly more risk averse in the fall/winter than in the spring/summer, on average, with the seasonal difference especially pronounced among depressed individuals. ${ }^{6}$ The evidence on and interest in seasonal depression make it clear that the condition is a very real and pervasive problem for a large segment of

\footnotetext{
${ }^{5}$ As Mersch (2001) and Thompson, Thompson, and Smith (2004) note, estimates of the prevalence of severe seasonal depression vary considerably, depending on the location, the diagnostic criteria, and the sample selection methods employed by the researchers. For example, Thompson et al. (2004) found that the prevalence of SAD in Britain ranged from 5.6\% to $10.7 \%$, depending on the diagnostic method. U.S. studies, such as Rosen, Targum, Terman, Bryant, Hoffman, Kasper, Hamovit, Docherty, Welch, and Rosenthal's (1990) study based on a sample in New Hampshire, find the incidence of SAD to be as high as $10 \%$. Others find that it is below $2 \%$, such as Rosen et al.'s (1990) study of a sample in Florida.

${ }^{6}$ Over the last couple of decades, a large industry has emerged in this area, for example, informing people how to deal with seasonal depression and offering products that create "natural" light to help
} 
the population. Individuals can begin to experience depressive effects or winter blues as early as July or August, but the bulk of people experience initial onset during the fall. Individuals may begin recovering early in the new year, as the days lengthen, although most experience symptoms until spring (see Lam (1998b) and Young et al. (1997)). Further, studies indicate that these seasonal changes in mood are more prevalent at higher latitudes (see, e.g., Magnusson (2000)) and that symptoms are milder close to the equator (see, e.g., Rosenthal et al. (1984)).

Regarding the second element of the link between seasons and risk aversion, there is substantial clinical evidence on the negative influence that a dampened mood has on risk-taking behavior. Pietromonaco and Rook (1987) find that depressed individuals take fewer social risks and seem to perceive risks as greater compared with nondepressed individuals. Carton, Jouvent, Bungenera, and Widlöcher (1992) and Carton, Morand, Bungenera, and Jouvent (1995) administered standardized risk-aversion questionnaires to depressed individuals, and they find that those individuals score as significantly more risk averse compared with nondepressed controls. Additional studies focus specifically on financial contexts. For instance, Smoski, Lynch, Rosenthal, Cheavens, Chapman, and Krishnan (2008) find that depressed people exhibit greater risk aversion in an experiment that includes monetary payoffs. Harlow and Brown (1990) document the connection between sensation seeking (a measure of inclination toward taking risk on which depressed individuals tend to score much lower than nondepressed individuals) and financial risk tolerance in an experimental setting involving a first-price sealed-bid auction. They find that one's willingness to accept financial risk is significantly related to sensation-seeking scores and to blood levels of neurochemicals associated with sensation seeking. ${ }^{7}$

In another experimental study, Sciortino, Huston, and Spencer (1987) examine the precautionary demand for money. They show that after controlling for various relevant factors, such as income and wealth, those individuals who score low on sensation-seeking scales (i.e., those who are relatively more risk averse) hold larger cash balances, roughly a third more than the average person, to meet unforeseen future expenditures. Further evidence is provided by Wong and Carducci (1991), who show that people with low sensation-seeking scores display greater risk aversion in making financial decisions, including decisions to purchase stocks, bonds, and automobile insurance, and by Horvath and Zuckerman (1993), who studied approximately 1,000 individuals in total and find that sensation-seeking scores are significantly positively correlated with the tendency to take financial risks.

Regarding the possibility that depressed individuals may exhibit passivity rather than risk aversion, Eisenberg, Baron, and Seligman (1998) conducted experiments in which individuals differing in their degree of depression were faced with a series of choices between pairs of risky and safe alternatives, including some of a financial nature. By setting the choices such that in some cases

sufferers cope with symptoms. Examples of popular books by leading researchers that are devoted to approaches for dealing with seasonal depression are those by Lam (1998a) and Rosenthal (2006).

${ }^{7}$ See Zuckerman (1983), (1994) for details on the biochemistry of depression and sensation seeking. 
the risky option was the default (not requiring action) and in other cases the safe option was the default, the researchers were able to distinguish risk aversion from passivity and found that depressive symptoms were correlated with risk aversion and not with passivity in making choices.

The evidence that risk aversion and negative sentiment vary seasonally (both for those who suffer from SAD and those who do not) motivates us to consider whether there is systematic seasonality in an individual investor's choice between alternative investments of different risk and, hence, systematic seasonality in the dollar flows between assets of differing risk classes.

\section{Measuring Seasonal Variation in Risk Preference}

We proxy for the influence of season on market participants' risk preference using a variable based on the timing of the onset of and recovery from depression among individuals who are known to suffer from SAD. ${ }^{8}$ The variable is constructed as follows, based on data compiled in a study of hundreds of SAD patients in Vancouver by Lam (1998b). ${ }^{9}$

First, we construct a seasonal-depression "incidence" variable, which reflects the monthly percentage of seasonal-depression sufferers who are actively experiencing symptoms in a given month. The incidence variable is constructed by cumulating, monthly, the percentage of seasonal-depression sufferers who have begun experiencing symptoms (cumulated starting in late summer when only a small proportion have been diagnosed with onset) and then deducting the cumulative percentage who have fully recovered. This incidence variable varies between $0 \%$ in summer and $100 \%$ in December/January. ${ }^{10}$ Because the variable is an estimate of the true timing of onset and recovery among seasonal-depression sufferers in the more general North American population, we use instrumental variables to correct for a possible error-in-variables bias (see Levi (1973)). ${ }^{11}$ Our

\footnotetext{
${ }^{8}$ In an untabulated analysis, we find that the results are qualitatively similar if, instead, we use a proxy based on the variation in daylight across the seasons, consistent with the established view of medical researchers that the driving force behind seasonal depression is reduced daylight. The proxy is the amount of time between sunset and sunrise (which is at its minimum at the summer solstice, increases most quickly at the autumn equinox, peaks at the winter solstice, and drops most quickly at the spring equinox). Note that the stock return regularity shown by Hirshleifer and Shumway (2003) considers sunshine, which is a function of cloud cover, in contrast to daylight, which does not depend on the weather.

${ }^{9}$ Young et al. (1997) similarly document the timing of SAD symptoms but for onset only. We base our measure on the Lam (1998b) data because they include the timing of both onset and recovery. Results are similar if we average the timing of onset from both the Lam and the Young et al. studies.

${ }^{10}$ The peak period during which individuals experience the onset of depression is in September and October. If investors begin shifting from risky to safe funds when they first become seasonally risk averse, then this period should correspond approximately with the period when many investors rearrange their portfolios. (In the extreme, investors who fully shed their risky holdings early in the fall may not be able to demonstrate through changes in their allocations any continued changes in risk aversion later in the season.) Similarly, in the new year, the peak period for reallocation from safe to risky funds should roughly align with the period when recovery from SAD peaks in March and April.

${ }^{11}$ To produce the instrumented version of incidence, first, we smoothly interpolate the monthly incidence of SAD to daily frequency using a spline function. Next, we run a logistic regression of the daily incidence on our chosen instrument, the length of day. (The nonlinear model is $1 /\left(1+e^{\alpha+\beta \mathrm{DAY}_{t}}\right)$, where $\mathrm{DAY}_{t}$ is the length of day $t$ in hours in New York, and $t$ ranges from 1 to 365 . This particular functional form is used to ensure that the fitted values lie on the range $0 \%$ to $100 \%$. The $\hat{\beta}$ coefficient
} 
findings are qualitatively unchanged whether we use the instrumented variable or the original variable. Finally, we calculate the monthly change in the instrumented series to produce the monthly onset/recovery variable that we use in this study. We denote onset/recovery as $\hat{\mathrm{OR}}_{t}$ (short for onset/recovery, with the hat indicating that the variable is the fitted value from a regression, as noted earlier). More specifically, the monthly variable $\hat{\mathrm{OR}}_{t}$ is calculated as the value of the daily instrumented incidence value on the 15th day of a given month minus the value of the daily instrumented incidence value on the 15 th day of the previous month. ${ }^{12}$

$\hat{\mathrm{OR}}_{t}$ reflects the change in the percentage of seasonal-depression-affected individuals actively suffering from depression. We consider the change rather than the level of depression-affected individuals because the change is a measure of the flow of depression-affected individuals, and we are attempting to model a flow variable, the flow of funds into and out of mutual funds. (We perform robustness checks using the change in the length of night rather than onset/recovery and find qualitatively identical results, as reported in Internet Appendix Section A-1, available at www.jfqa.org.) The monthly values of $\hat{\mathrm{OR}}_{t}$ are plotted with a thick line in Figure 1, starting with the first month of autumn, September. Notice that the measure is positive in the summer and fall and negative in the winter and spring. Its value peaks near the fall equinox and reaches a trough near the spring equinox. The movement in $\hat{\mathrm{OR}}_{t}$ over the year should capture the hypothesized opposing patterns in flows across the seasons, should they exist, without employing the two variables used by Kamstra et al. (2003): Neither the simple fall dummy variable nor the length-of-day variable they employed is necessarily directly related to the onset of and recovery from seasonal depression. ${ }^{13}$ For comparison, Figure 1 also includes plots of observed onset/recovery (thin plain line) and the change in length of night (normalized by dividing by 12 ; thin line with circles).

Some advantages of the instrumented onset/recovery variable are important to emphasize. First, it is based directly on the clinical incidence of seasonal depression in individuals, unlike Kamstra et al.'s (2003) hours-of-night variable. Second, the onset/recovery variable spans the full year, whereas Kamstra et al.'s (2003) length-of-night variable takes on nonzero values during the fall and winter months only and, therefore, does not account for the portion of individuals who experience seasonal depression earlier than fall or later than winter. (For a more complete discussion of the merits of the onset/recovery variable relative to Kamstra et al.'s (2003) original specification, see Kamstra, Kramer, and Levi (2012)). In light of these points, we conduct our analysis using the onset/recovery variable.

estimate is 1.18 with a standard error of 0.021 , the intercept estimate is -13.98 with a standard error of 0.246 , and the regression $R^{2}$ is $94.9 \%$.) The fitted value from this regression is the instrumented measure of incidence. Employing additional instruments, such as a change in the length of the day, makes no substantial difference in the fit of the regression or the subsequent results using this fitted value.

${ }^{12}$ The values of $\hat{\mathrm{OR}}_{t}$ by month, rounded to the nearest integer and starting with July, are as follows: $3,15,38,30,8,1,-5,-21,-42,-21,-5,0$. These values represent the instrumented net change in incidence of symptoms.

${ }^{13}$ In untabulated regressions, we compare the performance of $\hat{O R}_{t}$ to the two variables Kamstra et al. (2003) originally employed in their model, and we find qualitatively identical results. Importantly, conclusions relating to the existence of a seasonal cycle in mutual fund flows remain intact. 


\section{FIGURE 1}

\section{Onset/Recovery and Change in Length of Night}

The onset/recovery variable reflects the change in the proportion of seasonal-depression-affected individuals actively suffering from depression. The monthly series, calibrated to the 15th day of each month, is based on the clinical incidence of symptoms among patients who suffer from the condition. The thick plain line plots the onset/recovery variable $\left(\hat{O R} \hat{R}_{t}\right)$, the thin plain line plots observed onset/recovery, and the line with circles is the change in the number of hours of night, divided by 12 (where 12 is the annual average daily number of hours of night).

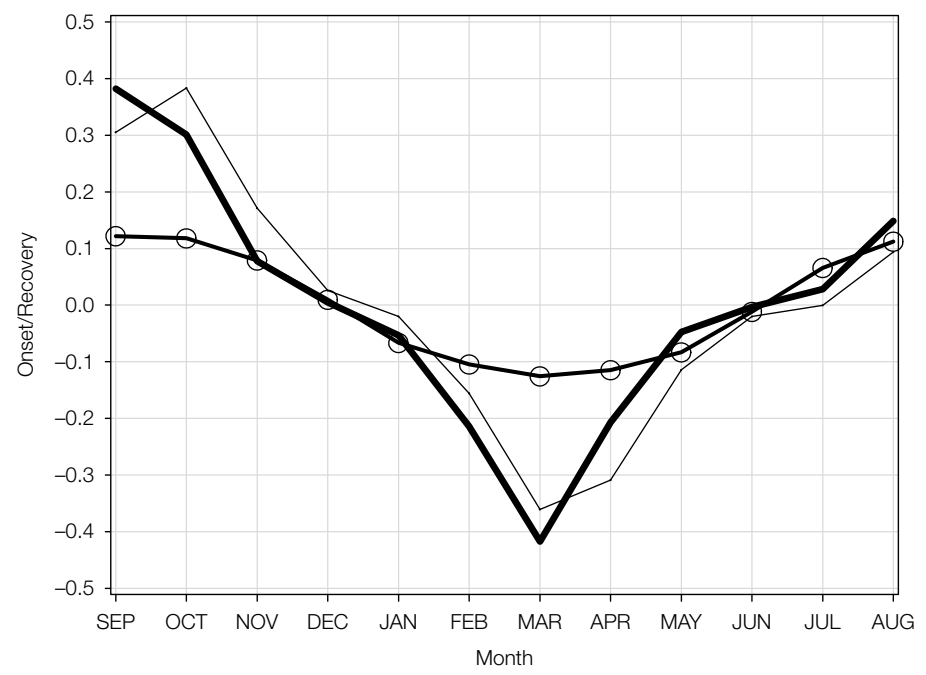

\section{Data}

We obtained the U.S. data sets from the ICI. These data consist of monthly flows to 30 mutual fund investment objective categories, covering the period of Jan. 1, 1984 to Jan. 31, 2010. ${ }^{14}$ The need for lagged values restricts the range of data used in our regression analysis to start in Feb. 1985, and concerns about the chaotic flows during the financial crisis, in particular, flows in and out of money market funds, motivates us to end the sample in Dec. 2006 for the purposes of model estimation. ${ }^{15}$ (Nonetheless, in robustness tests, we find that the results are qualitatively unchanged if we extend the sample period to include the financial crisis. See Internet Appendix Section A-2 for regression results based on the full set of data provided to us by the ICI, ending in 2010.) For each investment objective category during each month, the ICI provides the total sales, redemptions,

${ }^{14}$ The ICI provides data for 33 fund categories in total. However, we omit three from the analysis: Taxable Money Market-Non-Government, National Tax-Exempt Money Market, and State TaxExempt Money Market. Although these are ostensibly similar to the money market category (which includes only funds classified as Taxable Money Market-Government), we sought a money market category that represents the safest category of funds. Schmidt, Timmermann, and Wermers (2016) show evidence that investors considered the Taxable Money Market-Government category as the safe haven during the money fund crisis of September 2008. Our results are qualitatively unchanged if, instead, we include these three omitted investment objective categories in the money market category.

${ }^{15}$ For example, Schmidt et al. (2016) show that flows to and from money funds during September 2008 were largely driven by fears of prime money funds "breaking the buck." 
exchanges, reinvested distributions, and (end-of-month) total net assets (TNA), aggregated across all mutual funds within that category. Exchanges consist of exchanges from other same-family funds into a given fund (exchanges in) and exchanges from a given fund to other same-family funds (exchanges out). Note that our primary analysis utilizes flows and exchanges associated with both retail and institutional share classes. In Internet Appendix Section A-3, we show that our findings are robust to use of retail-share-class-only flows or exchanges. ${ }^{16}$

Table 1 shows the categories of funds we employ. We group the fund categories into five asset classes: "equity," "hybrid," "corporate fixed income," "government fixed income," and "money market." (In Internet Appendix Section A-4, we show that the results are robust to a less coarse classification into nine asset classes.) Flows and assets are aggregated across all investment objective categories within an asset class to arrive at asset-class-level flows and

\section{TABLE 1}

\section{Classification of U.S. Mutual Funds}

\begin{tabular}{lll}
$\begin{array}{l}\text { In Table 1, we map funds from } 30 \text { investment objective categories into a set of } 5 \text { asset classes, based on characteristics } \\
\text { of the individual funds provided in the ICI (2003) Mutual Fund Fact Book. }\end{array}$ & Asset Class \\
\cline { 2 - 3 } Fund Number & \multicolumn{1}{c}{ ICI Fund } & Equity \\
\cline { 2 - 3 } 1 & Aggressive growth & Equity \\
2 & Growth & Equity \\
3 & Sector & Equity \\
4 & Emerging markets & Equity \\
5 & Global equity & Equity \\
6 & International equity & Equity \\
7 & Regional equity & Equity \\
8 & Growth and income & Equity \\
9 & Income equity & Hybrid \\
10 & Asset allocation & Hybrid \\
11 & Balanced & Hybrid \\
12 & Flexible portfolio & Hybrid \\
13 & Income mixed & Corporate fixed income \\
14 & Corporate-general & Corporate fixed income \\
15 & Corporate-intermediate & Corporate fixed income \\
16 & Corporate-short term & Corporate fixed income \\
17 & High yield & Corporate fixed income \\
18 & Global bond-general & Corporate fixed income \\
19 & Global bond-short term & Corporate fixed income \\
20 & Other world bond & Government fixed income \\
21 & Government bond-general & Government fixed income \\
22 & Government bond-intermediate & Government fixed income \\
23 & Government bond-short term & Government fixed income \\
24 & Mortgage backed & Corporate fixed income \\
25 & Strategic income & Government fixed income \\
26 & State municipal bond-general & Government fixed income \\
27 & State municipal bond-short term & Government fixed income \\
28 & National municipal bond-general & Government fixed income \\
29 & National municipal bond-short term & Money market \\
30 & Taxable money market-government & \\
\hline & & \\
\hline
\end{tabular}

\footnotetext{
${ }^{16}$ Note that the retail-share-class-only subset of the data we consider in the Internet Appendix consists solely of retail share classes. We are unable to consider the pure set of investors that excludes all retail investors or the set that includes all retail investors because our primary data set does not distinguish between true "institutional" investors and those so-called institutional investors that consist of a group of individuals (e.g., the defined-contribution sample of Sialm, Starks, and Zhang (2015)).
} 
combined assets. ${ }^{17}$ We compute "active" net monthly flows to asset class $i$ during month $t$, as a percentage of end-of-month $t-1$ TNA, as follows:

$$
\begin{aligned}
& \text { NET_FLOW }_{i, t} \\
& =\frac{\text { SALES }_{i, t}-\text { REDEMPTIONS }_{i, t}+\text { EXCHANGES_IN }_{i, t}-\text { EXCHANGES_OUT }_{i, t}}{\text { TNA }_{i, t-1}} .
\end{aligned}
$$

Consistent with the literature, we treat reinvested dividends as passive and do not include them in our net flows measure.

Another measure of flows we consider is monthly net exchanges to asset class $i$ during month $t$, as a percentage of end-of-month $t-1$ TNA:

$$
\text { NET_EXCHANGE }_{i, t}=\frac{\text { EXCHANGES_IN }_{i, t}-\text { EXCHANGES_OUT }_{i, t}}{\text { TNA }_{i, t-1}} .
$$

Net exchanges are not subject to certain confounding effects that may complicate the study of net flows, including income flows (i.e., liquidity considerations such as tax refund cash flows, year-end bonuses, and changes in savings/expenditure behavior).

In Table 2, we report summary statistics for the data, including monthly asset-class fund net flows in Panel A, monthly asset-class net exchanges in Panel B, explanatory variables used in the regression models in Panel C (supplemental information about many of these explanatory variables appears in Internet Appendix Section A-5), and value-weighted excess returns in Panel D. As previously mentioned, fund flows are reported as a percentage of the fund's prior end-of-month total net assets. Also note that the summary statistics cover our entire available sample, Feb. 1984 through Jan. 2010. We report the statistics based on this long sample period because our robustness checks are based on various sample periods (including dates beyond the 2006 end date for our primary regression analysis) and because we use lags of the data back to 1984 in our analysis.

In Panel A of Table 2, we see that the mean monthly equity class net flow is $0.504 \%$ of equity class TNA. The hybrid class has a mean monthly net flow of approximately $0.733 \%$ of hybrid TNA, and the corporate fixed-income class has very similar mean flows of $0.756 \%$ of TNA. The government fixed-income class has mean monthly flows of approximately $0.782 \%$ of TNA, and the money market asset class has mean monthly flows of approximately $0.581 \%$ of TNA. The standard deviations of monthly asset-class net flows range from a low of $0.84 \%$ for the equity class to a high of well over $2 \%$ for the money market and government fixed-income classes.

Panel B of Table 2 displays net exchanges, which should, and do, net across asset classes to within a few basis points of 0 (after weighting by the respective asset-class prior-month asset values). The volatility of net exchanges is smaller than that of net flows, and the skewness is a mix of negative and positive, compared with the consistent positive skewness of net flows across fund classes.

\footnotetext{
${ }^{17}$ We weight by TNA when computing variables such as asset-class returns, and we aggregate dollar flows to arrive at aggregate flows for an asset class.
} 
In Panel $\mathrm{C}$ of Table 2, we first present statistics for the explanatory variables used in the regression analysis that follows. Our advertising variable is monthly print advertisement expenditures by mutual fund families (detrended by dividing by the previous year's total advertisement expenditure to account for

\section{TABLE 2}

\section{Summary Statistics on U.S. Monthly Percentage Asset-Class Net Exchanges, Explanatory Variables, and Associated Returns to Holding These Funds}

Table 2 contains summary statistics on U.S. monthly fund percentage net flows, percentage net exchanges, explanatory variables, and returns over Feb. 1984 through Jan. 2010, for a total of 312 months (with the exception of $R^{\text {YEAR }}$, the return-chasing measure, for which the data start in Feb. of 1985, and $R^{\text {CAP_GAINS }}$, the capital-gains measure, for which we have data from Nov. 1984 to Jan. 2007). Flows data are from the $\mathrm{ICl}$, and returns were calculated using fund flow and TNA changes available from the $\mathrm{ICl}$. The returns in Panel D are in excess of the 30-day T-bill rate, with the 30-day T-bill rate available from CRSP. $R^{\text {CAP_GAINS }}$, the capital-gains measure, equals the realized capital-gains return to holding the fund from the previous year's Nov. 1 '(the start of the tax year for U.S. mutual funds) to the current year's Oct. 31. $R^{\mathrm{YEAR}}$ is the mean monthly fund percentage return over the prior 12 months, to capture return chasing. The advertising variable is monthly print advertisement expenditures by mutual fund families, detrended by dividing by the previous year's total advertisement expenditure, resulting in a proportion. The advertising data originate from Figure 3 of Gallaher et al. (2006). Savings are based on real disposable income and expenditures as a percentage of real disposable income, annualized, obtained from the Bureau of Economic Analysis. For each set of fund flows and returns, we present the mean monthly values (Mean), standard deviation (Std. Dev.), minimum (Min), maximum (Max), skewness (Skew), and kurtosis (Kurt). For excess returns, we also present the capital asset pricing model (CAPM) beta and the coefficient estimate on the onset/recovery variable, each estimated in a separate regression. These coefficients are produced in a systemequation estimation using the seemingly unrelated regression technique and MacKinnon and White (1985) bootstrap heteroskedasticity-consistent standard errors. We use the CRSP value-weighted total market return, including dividends, for the market return. The instruments used for the onset/recovery regression are the onset/recovery variable (ÔR) and a constant. ${ }^{*},{ }^{* *}$, and ${ }^{* * *}$ indicate significance at the $10 \%, 5 \%$, and $1 \%$ levels, respectively, based on 2 -sided tests.

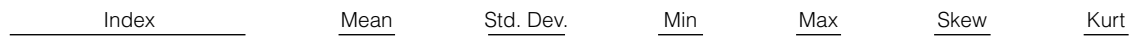

Panel A. Asset-Class Percentage Net Flows

$\begin{array}{ll}\text { Equity } & 0.504 \\ \text { Hybrid } & 0.733 \\ \text { Corporate fixed income } & 0.756 \\ \text { Government fixed income } & 0.782 \\ \text { Money market } & 0.581\end{array}$

0.84
1.32
1.19
2.21
2.83

-3.17
-2.28
-2.29
-3.62

$-3.62$

Panel B. Asset-Class Percentage Net Exchanges

$\begin{array}{ll}\text { Equity } & -0.045 \\ \text { Hybrid } & -0.043 \\ \text { Corporate fixed income } & -0.020 \\ \text { Government fixed income } & -0.062\end{array}$

Government fixed income $\quad-0.062$

Money Market

Panel C. Explanatory Variables

$\begin{array}{lc}\text { Advertising } & 1.010 \\ \text { Savings } & 1.513 \\ \text { Equity-Fund Specific } & \\ R^{\text {CAP_GAINS }} & 3.416 \\ R^{\text {YEAR }} & 0.982 \\ \text { Hybrid-Fund Specific } & \\ R^{\text {CAP_GAINS }} & 1.817 \\ R^{\text {YEAR }} & 0.707 \\ \text { Corporate-Fixed-Income-Fund Specific } \\ R^{\text {CAP_GAINS }} & 0.413 \\ R^{\text {YEAR }} & 0.766 \\ \text { Government-Fixed-Income-Fund Specific } \\ R^{\text {CAP_GAINS }} \\ R^{\text {YEAR }} & 0.232 \\ R^{\text {Money-Market-Fund Specific }} & 0.445 \\ R^{\text {CAP_GAINS }} & \\ R^{\text {YEAR }} & 0.00\end{array}$


TABLE 2 (continued)

Summary Statistics on U.S. Monthly Percentage Asset-Class Net Exchanges, Explanatory Variables, and Associated Returns to Holding These Funds

\begin{tabular}{|c|c|c|c|c|c|c|c|c|}
\hline Index & Mean & Std. Dev. & Min & Max & Skew & Kurt & Beta & $\hat{\mathrm{OR}}$ \\
\hline \multicolumn{9}{|c|}{$\underline{\text { Panel D. Asset-Class Excess Returns }}$} \\
\hline $\begin{array}{l}\text { Equity } \\
\text { Hybrid } \\
\text { Corporate fixed income } \\
\text { Government fixed income } \\
\text { Money market }\end{array}$ & $\begin{array}{l}0.621 \\
0.358 \\
0.411 \\
0.085 \\
0.201\end{array}$ & $\begin{array}{l}4.50 \\
2.76 \\
1.49 \\
1.22 \\
1.29\end{array}$ & $\begin{array}{r}-20.85 \\
-12.72 \\
-8.02 \\
-6.58 \\
-2.75\end{array}$ & $\begin{array}{r}19.09 \\
8.44 \\
6.65 \\
3.99 \\
12.07\end{array}$ & $\begin{array}{r}-0.768 \\
-0.917 \\
-0.504 \\
-0.740 \\
4.066\end{array}$ & $\begin{array}{r}3.49 \\
2.71 \\
4.15 \\
3.23 \\
30.48\end{array}$ & $\begin{array}{l}0.970^{* * \star} \\
0.583^{* * \star} \\
0.167^{* * *} \\
0.069^{* * \star} \\
-0.044^{*}\end{array}$ & $\begin{array}{l}-2.526^{\star \star} \\
-1.372^{\star} \\
-0.235 \\
0.545 \\
0.629\end{array}$ \\
\hline Asset Class & & Equity & & brid & & $\begin{array}{c}\text { Corporate } \\
\text { Fixed Income } \\
\end{array}$ & & $\begin{array}{l}\text { Government } \\
\text { Fixed Income } \\
\end{array}$ \\
\hline \multicolumn{9}{|c|}{ Panel E. Asset-Class Net Flow Correlations } \\
\hline $\begin{array}{l}\text { Hybrid } \\
\text { Corporate fixed income } \\
\text { Government fixed income } \\
\text { Money market }\end{array}$ & & $\begin{array}{r}0.625^{\star \star \star} \\
0.343^{\star \star \star} \\
0.203^{* \star *} \\
-0.200^{* \star *}\end{array}$ & & $\begin{array}{l}84^{\star \star \star} \\
96^{\star \star \star} \\
50^{\star \star \star}\end{array}$ & & $\begin{array}{l}0.718^{\star \star \star} \\
-0.070\end{array}$ & & -0.040 \\
\hline \multicolumn{9}{|c|}{ Panel F. Asset-Class Net Exchange Correlations } \\
\hline $\begin{array}{l}\text { Hybrid } \\
\text { Corporate fixed income } \\
\text { Government fixed income } \\
\text { Money market }\end{array}$ & & $\begin{array}{l}0.292^{* * *} \\
0.252^{* \star *} \\
0.196^{\star * \star} \\
-0.730^{\star * \star}\end{array}$ & & $\begin{array}{l}87^{\star \star *} \\
16^{\star \star} \\
80^{\star \star *}\end{array}$ & & $\begin{array}{r}0.607^{\star \star \star} \\
-0.490^{\star \star \star}\end{array}$ & & $-0.470^{\star \star \star}$ \\
\hline
\end{tabular}

time-series trend-line growth). ${ }^{18}$ We calculate savings using consumption expenditures and income data from the Bureau of Economic Analysis (BEA). ${ }^{19}$ Advertisements trend upward during the sample period even after detrending by the 12-month moving average, although only slightly, and savings average to over $1.5 \%$ per month. Even the more conservative BEA personal savings rate (which is reported in the press) shows an average monthly savings rate of $0.4 \%$ per month over this period. ${ }^{20} R^{\text {YEAR }}$ is the mean monthly fund percentage return over the prior 12 months, a return-chasing measure, and $R^{\text {CAP_GAINS }}$ is the realized capital-gains return for each class, our primary measure of capital-gains overhang. (We provide results from extensive robustness checks on the return-chasing and capital-gains overhang measures. See Section VII for a very detailed summary and Internet Appendix Section A-1 for tabled results.) $R^{\mathrm{YEAR}}$ is the mean monthly return over the prior 12 months, and $R_{i, t}^{\text {CAP_GAINS }}$ equals the realized capital-gains return to holding the fund from the previous Nov. 1 (the start of the tax year for mutual funds) to date $t-1$. The mean cumulative capital-gains returns decline monotonically from a high of approximately $3.4 \%$ for the equity-fund category through the categories of hybrid, corporate bond, government bond, and money market funds.

\footnotetext{
${ }^{18}$ We obtain the monthly advertising expenditure data from Gallaher et al. ((2006), Figure 3). Their series covers advertisements in more than 288 print publications over 1992-2001; for sample dates outside that period we use the average monthly values calculated using the 1992-2001 period. Reuter and Zitzewitz (2006) report that most mutual fund advertisements are print ads.

${ }^{19}$ Specifically, the savings variable is calculated by subtracting Real Personal Consumption Expenditures (BEA series ID PCEC96) from Real Disposable Personal Income (BEA series ID DSPIC96), divided by DSPIC96, multiplying by 100, and dividing by 12 .

${ }^{20}$ We have conducted robustness checks using the BEA personal savings rate (series ID PSAVERT) in place of the savings variable based on series IDs PCEC96 and DSPIC96 and found that all three series behave very similarly, with the use of the BEA personal savings rate making only minor qualitative changes to the results.
} 
Government bond funds report an average cumulative capital gain return of only approximately 23 basis points (bps), roughly 1/15 of that reported by equity funds. Money market funds have virtually no capital gains to distribute, and so this fund category exhibits an average cumulative capital-gains return of less than $0.01 \mathrm{bps}$.

The first six columns of Panel D in Table 2 contain summary statistics on the monthly excess asset-class returns: mean, standard deviation, minimum, maximum, skewness, and kurtosis. ${ }^{21}$ We calculate the return to holding a fund as is conventional in the literature and as provided by the ICI; the return for month $t$ and asset class $i$ is $R_{i, t}=\frac{\mathrm{TNA}_{i, t}-\mathrm{TNA}_{i, t-1}-\mathrm{NET}_{-} \mathrm{FLOW}_{i, t}}{\mathrm{TNA}_{i, t-1}}{ }^{22}$ The asset-class return data reveal familiar patterns, with equity returns being the largest and the most volatile, loosely declining across categories. We report additional metrics in the last two columns of Panel D. In the second-to-last column, we see that the excess returns show a monotonically declining CAPM beta from top to bottom, suggesting a declining exposure to systematic risk across this ordering of fund asset classes. The last column contains coefficient estimates from regressing excess returns on onset/recovery. ${ }^{23}$ These estimates indicate that riskier fund returns tend to be negatively correlated with onset/recovery, whereas safer fund returns tend to be positively correlated with onset/recovery. ${ }^{24}$ Later, we report the results of conditional analysis based on fund flows, our primary focus of interest.

Finally, in Panels E and F of Table 2 we present net flow and net exchange correlations across fund categories. For net flows (Panel E), we note that correlations between riskier categories, such as equity and corporate fixed income, are generally much higher than correlations between high- and low-risk categories, such as equity and money market. For net exchanges, it is even clearer that households chiefly move money between the risky categories and the money market category. Overall, the correlations appear consistent with the notion that households move money between categories, treating fund classes with similar risk and return profiles as complements and treating risky and safe categories as substitutes.

\footnotetext{
${ }^{21}$ Our excess returns are calculated conventionally, using the 30-day T-bill rate as the risk-free proxy return, sourced from CRSP.

${ }^{22}$ Note that this expression assumes that all distributions are reinvested because we do not include distributions in our computation of flows. Our discussions with staff at the ICI indicate that over $80 \%$ of investors reinvest capital-gains and dividend distributions. Because we conduct many robustness checks on the impact of returns on flows, we do not believe that this assumption is critical; indeed, the various permutations we consider when evaluating the impact of returns on flows make little or no difference to the core results on seasonality in flows. Further, one of our robustness checks makes use of fund returns from the CRSP Mutual Fund Database, which provides actual returns to holding funds. Our findings are virtually identical based on the realized returns provided by CRSP.

${ }^{23}$ The CAPM beta and the coefficient estimate on the onset/recovery variable are estimated in separate regressions. These coefficient estimates are produced in a system-equation estimation using the seemingly unrelated regression technique and MacKinnon and White (1985) bootstrap heteroskedasticity-robust standard errors.

${ }^{24}$ Recall that the onset/recovery variable is itself positive in the fall and negative in the winter, so the implication is higher-than-average (lower-than-average) returns in safe (risky) categories in the fall and lower-than-average (higher-than-average) returns in the safe (risky) categories in the spring. These findings are consistent with studies that examine risky and safe securities outside the context of mutual fund flows. Specifically, Kamstra et al. (2003) find lower-than-average stock returns in the fall and higher-than-average stock returns in the spring, and Kamstra et al. (2015) find higher-thanaverage returns to safe U.S. Treasury securities in the fall and lower-than-average Treasury returns in the spring.
} 


\section{Results}

This section contains our primary results, starting with a graphical examination of flows seasonality. Then we turn to regression analysis, first focusing on net flows, which include flows between fund families as well as sales and redemptions. Next, we consider net exchanges, that is, within-family movements of money, such as a movement from a Fidelity equity fund to a Fidelity money market fund. Net exchanges are more immune to liquidity-related reasons to move money into or out of fund categories. For example, net exchanges would not be impacted by someone buying equity funds with year-end bonus money or selling funds for a large purchase. After discussing estimation results for both sets of flow measures, we discuss the economic magnitude of the findings.

\section{A. Seasonality in Average Monthly Flows}

In Figure 2, we consider seasonality in average monthly asset-class fund flows. Again, conditional regression analysis follows. The monthly average flows (averaged across all years from 1985 to 2006) for the equity and money market asset classes appear in Graphs A and B, respectively, with thick solid lines. Each plot starts with the first month of autumn. The seasonal patterns in average monthly equity and money market flows are consistent with seasonality in risk aversion having an impact on flows. During the fall months, as daylight diminishes, individuals become depressed and more risk averse. If their risk aversion causes them to shift assets away from risky asset classes and toward safe asset classes, we should see net equity (money market) flows that are lower (higher) than average in the fall months, and we do. Similarly, as daylight becomes more plentiful in the winter months through to the spring, investors affected by seasonal depression revert to their previous level of risk aversion and become more willing to hold risky funds. Accordingly, we see that equity (money market) net

\section{FIGURE 2}

\section{Average Monthly U.S. Net Flows and Predicted Flows Due to Onset/Recovery: Equity and Money Market}

Graph A of Figure 2 contains monthly average equity asset-class fund net flows as a percentage of prior-month equity class TNA, indicated with a thick solid line, and average fitted values implied by the onset/recovery coefficient from estimating equation (1), indicated with a dashed line with diamonds. Graph B contains monthly average money market asset-class fund net flows as a percentage of prior-month money market TNA, indicated with a thick solid line, and average fitted values implied by the onset/recovery coefficient from estimating equation (1), indicated with a dashed line with diamonds. The plots also include a $90 \%$ confidence interval around the monthly means (shown with thin dashed lines) and the average flow throughout the year (represented by solid lines with circles and an $\mathrm{x}$ mark in cases where the average return falls outside of the confidence interval). The data, provided by the Investment Company Institute, span Jan. 1985-Dec. 2006.

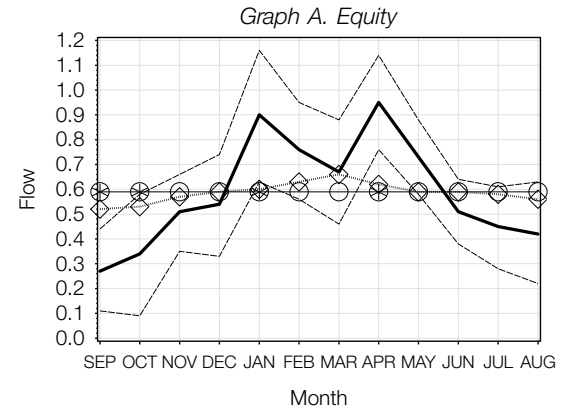

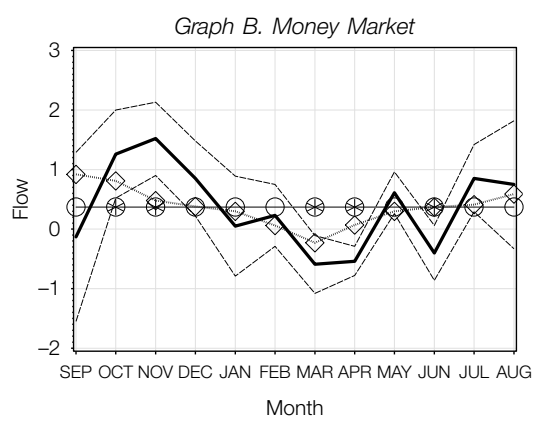


flows are higher (lower) than average during that period. Overall, the flows in the summer/fall and winter/spring are consistent with depression-affected individuals shifting their portfolios between risky and safe funds depending on their seasonally varying risk aversion. Of course, other factors may underlie these seasonal patterns, and we explore alternative explanations in the conditional analysis that appears in the next subsection.

The thin dotted lines surrounding the thick lines in Figure 2 are the $90 \%$ confidence intervals around the average monthly flows. ${ }^{25}$ Consistent with the intuition from the seasonal pattern of flows, we see several instances of statistically significant deviations of the equity (money market) fund flows from annual mean flows, lower (higher) in the summer/fall and higher (lower) in the winter/spring. The dashed line marked with diamonds represents the average monthly fitted values from a regression model that includes onset/recovery as an explanatory variable. We develop this model fully later in the paper, but for now, we simply note that the fitted value from onset/recovery, controlling for other effects such as capital gains, liquidity needs, year-end flows from reinvestment of distributions and bonus pay, and autocorrelation in flows, tracks the unconditional seasonal pattern in flows fairly well.

Omitted plots for the hybrid class, corporate fixed-income class, and government fixed-income class show seasonal flow patterns that lie between the extremes of equity and money market fund flows. This is perhaps not surprising, given that these other classes are intermediate in their exposure to risk relative to equity and money market asset classes, as measured by fund excess return beta and onset/recovery coefficient estimates as shown in Table 2 and consistent with practitioner classifications of the risk involved in holding these various fund classes.

\section{B. The Net Flows Regression Model}

We turn now to regression analysis. There is considerable autocorrelation in fund flows, so we estimate a model that incorporates lags of the dependent variable to control directly for autocorrelation. Specifically, we include a 1-month lag and a 3-month lag of the dependent variable as regressors. In the Internet

\footnotetext{
${ }^{25}$ There are several approaches one could adopt to calculate the confidence interval around the mean monthly net flows. The simplest is to use the standard deviation of the monthly mean flows directly. However, this would ignore information about the cross-sectional variability of flows across the fund asset classes. Instead, we form a system of equations with the flows data and estimate a fixedeffects model with 12 dummy variables (one for each month). In order to leverage the information in the cross section more effectively, we work with slightly more disaggregated data than the five fund classes, using instead the nine classes described herein. Consistent with the typical implementation of a fixed-effects model, we allow each subclass series within an asset class to have a different mean while estimating a single set of parameter values for the variables each subclass series in an asset class has in common, in this case, the monthly dummy variables. The equity fund asset class is split into two subclasses, "risky equity" and "safe equity." "Hybrid" remains as previously defined. "Corporate fixed income" is split into "global bond" and "U.S. corporate bond." "Government fixed income" is split into "munis," "medium- and short-term government," and "general-term government." The "money market" asset class remains as previously defined. From this regression, we obtain the standard errors on the fund flow monthly dummies to form the confidence intervals around the monthly mean flows. To calculate the standard errors, we follow Newey and West (1987), (1994) and use the Bartlett kernel and an automatic bandwidth parameter (autocovariance lags) equal to the integer value of $4(T / 100)^{2 / 9}$. The instruments used for the regression are the 12 monthly dummy variables.
} 
Appendix, we consider variations on the number of lags. The complete model we estimate is as follows:

$$
\begin{aligned}
\text { NET_FLOW }_{i, t}= & \mu_{i}+\mu_{i, \hat{\mathrm{OR}}} \hat{\mathrm{OR}}_{t}+\mu_{i, \mathrm{ADS}} \mathrm{ADS}_{t}+\mu_{i, R} \mathrm{YEAR} R_{i, t}^{\mathrm{YEAR}} \\
& +\mu_{i, \mathrm{CAP} \_\mathrm{GAINS}} R_{i, t}^{\mathrm{CAP}_{\text {GAINS }}}+\mu_{i, \mathrm{NOV} \mathrm{NOV}_{t}}+\mu_{i, \mathrm{DEC}} \mathrm{DEC}_{t} \\
& +\mu_{i, \mathrm{JAN}} \mathrm{JAN}_{t}+\mu_{i, \mathrm{FEB}} \mathrm{FEB}_{t}+\mu_{i, \mathrm{SAVINGS}} \mathrm{SAVINGS}_{t-1} \\
& +\rho_{i, 1} \mathrm{NET}_{2} \mathrm{FLOW}_{i, t-1}+\rho_{i, 3} \mathrm{NET}_{\mathrm{FLOW}} \mathrm{OW}_{i, t-3}+\epsilon_{i, t},
\end{aligned}
$$

where $i$ references the mutual fund asset class. The dependent variable, NET_FLOW $_{i, t}$, is the month $t$ fund net flow expressed as a percentage of month $t-1$ total net assets. $\hat{\mathrm{OR}}_{t}$ is the onset/recovery variable. The remaining explanatory variables are defined in Section IV, with additional information appearing in Internet Appendix Section A-5. Briefly, SAVINGS ${ }_{t}$ is personal savings, included as a control variable for investor liquidity needs, which might also affect fund flows in a seasonal way. (We lag savings by 1 month to avoid endogeneity because individual investors make savings decisions simultaneously with decisions regarding mutual fund flows.) $R_{i, t}^{\mathrm{YEAR}}$ is the return to fund asset class $i$ over the prior 12 months (i.e., from month $t-13$ through month $t-1$ ), included to control for return-chasing flows. $R_{i, t}^{\text {CAP_GAINS }}$ is included to control for the influence of capital-gains overhang on flows and equals the realized capital-gains return to holding the fund from the previous year's Nov. 1 (the start of the tax year for mutual funds) to month $t-1$. $\mathrm{ADS}_{t}$ is monthly print advertisement expenditures by mutual fund families (normalized by the prior year's ad expenditures). $\mathrm{NOV}_{t}, \mathrm{DEC}_{t}, \mathrm{JAN}_{t}$, and $\mathrm{FEB}_{t}$ are dummy variables for monthly flows, taking on values of 1 in the indicated month, and 0 elsewhere. These dummies are included to capture turn-of-the-year effects driven by factors beyond simple capital-gains tax avoidance, including the reinvestment of dividend and capital-gains distributions in the months after the distributions are made and the impact of year-end bonuses on flows, both of which may be influencing flows in November through February. We provide multiple robustness checks on this base specification, detailed in Internet Appendix Section A-1. For instance, we exclude the November through February dummy variables from the model, and we use alternate capitalgains measures and return chasing, among other checks. In each case, the results are qualitatively identical to those we present here.

We estimate equation (1) as a system of equations across asset classes using Hansen's (1982) generalized methods of moments (GMM) and Newey and West (1987), (1994) heteroskedasticity- and autocorrelation-consistent (HAC) standard errors. ${ }^{26}$ Results from estimating this set of equations appear in Table 3. In Panel A

\footnotetext{
${ }^{26}$ Our use of HAC standard errors is due to the fact that autocorrelation and heteroskedasticity are prominent features of flows for all asset classes. See Warther (1995), Remolona, Kleiman, and Gruenstein (1997), and Karceski (2002), among others. To calculate standard errors, we follow Newey and West (1994) and use the Bartlett kernel and an automatic bandwidth parameter (autocovariance lags) equal to the integer value of $4(T / 100)^{2 / 9}$. The instruments used for the regression include the full set of explanatory variables. We also explored the use of seemingly unrelated panel regression estimation with MacKinnon and White (1985) bootstrap heteroskedasticity-robust standard errors and sufficient lags to control for autocorrelation. This approach yields similar results to GMM for both significance and magnitude of effects; individual $t$-tests on variables tend to be smaller, but joint tests of significance show strong statistical significance.
} 


\section{TABLE 3}

\section{Regression Results for U.S. Asset-Class Net Flows}

In Table 3, we report coefficient estimates from jointly estimating the following regression for each U.S. asset class in a GMM framework:

$$
\begin{aligned}
& \text { NET_FLOW }_{i, t}=\mu_{i}+\mu_{i, \mathrm{OR}} \hat{\mathrm{OR}}_{t}+\mu_{i, \mathrm{ADS}} \mathrm{ADS}_{t}+\mu_{i, R^{\mathrm{YEAR}}} R_{i, t}^{\mathrm{YEAR}}
\end{aligned}
$$

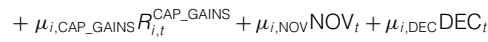

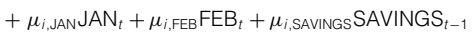

$$
\begin{aligned}
& +\rho_{i, 1} \text { NET_FLOW }_{i, t-1}+\rho_{i, 3} \text { NET_FLOW }_{i, t-3}+\epsilon_{i, t} \text {. }
\end{aligned}
$$

The data used to estimate the model span Feb. 1985 through Dec. 2006. The monthly net flows are computed as sales, minus redemptions, plus exchanges in, minus exchanges out, all divided by the previous month's total net assets. The explanatory variables are defined in the text. In Panel A, we present coefficient estimates with HAC robust $t$-tests (reported in parentheses). At the bottom of Panel A, we present the value of adjusted $R^{2}$ for each estimation, a Wald $\chi^{2}$ test statistic for the presence of up to 12 lags of autocorrelation (AR), and a Wald $\chi^{2}$ test statistic for the presence of up to 12 lags of ARCH (both with 12 degrees of freedom). The test for ARCH is a standard Lagrangian multiplier (LM) test of order 12. See Engle (1982). To perform the test for autocorrelation, we augment the regression with 12 lags of the residuals, estimate MacKinnon and White (1985) bootstrap heteroskedasticity-consistent standard errors with ordinary least squares (OLS), and test for the joint significance of these terms. Panel B contains joint test statistics. The first is a $\chi^{2}$ statistic (with 5 degrees of freedom) testing the null that the onset/recovery coefficient estimates are jointly 0 across the asset classes, the second is a $\chi^{2}$ statistic (with 4 degrees of freedom) testing the null that the onset/recovery coefficient estimates are jointly equal to each other across the asset classes, and the third is the Hansen (1982) $\chi^{2}$ goodness-of-fit test of the model based on the optimized value of the objective function produced by GMM. To calculate the standard errors, we follow Newey and West (1987), (1994) and use the Bartlett kernel and an automatic bandwidth parameter (autocovariance lags) equal to the integer value of $4(T / 100)^{2 / 9}$. We use the full set of explanatory variables as instruments for the regression. ${ }^{*}$, **, and ${ }^{* * *}$ indicate significance at the $10 \%, 5 \%$, and $1 \%$ levels, respectively, based on 2 -sided tests.

Panel A. Parameter Estimates and Diagnostic Statistics

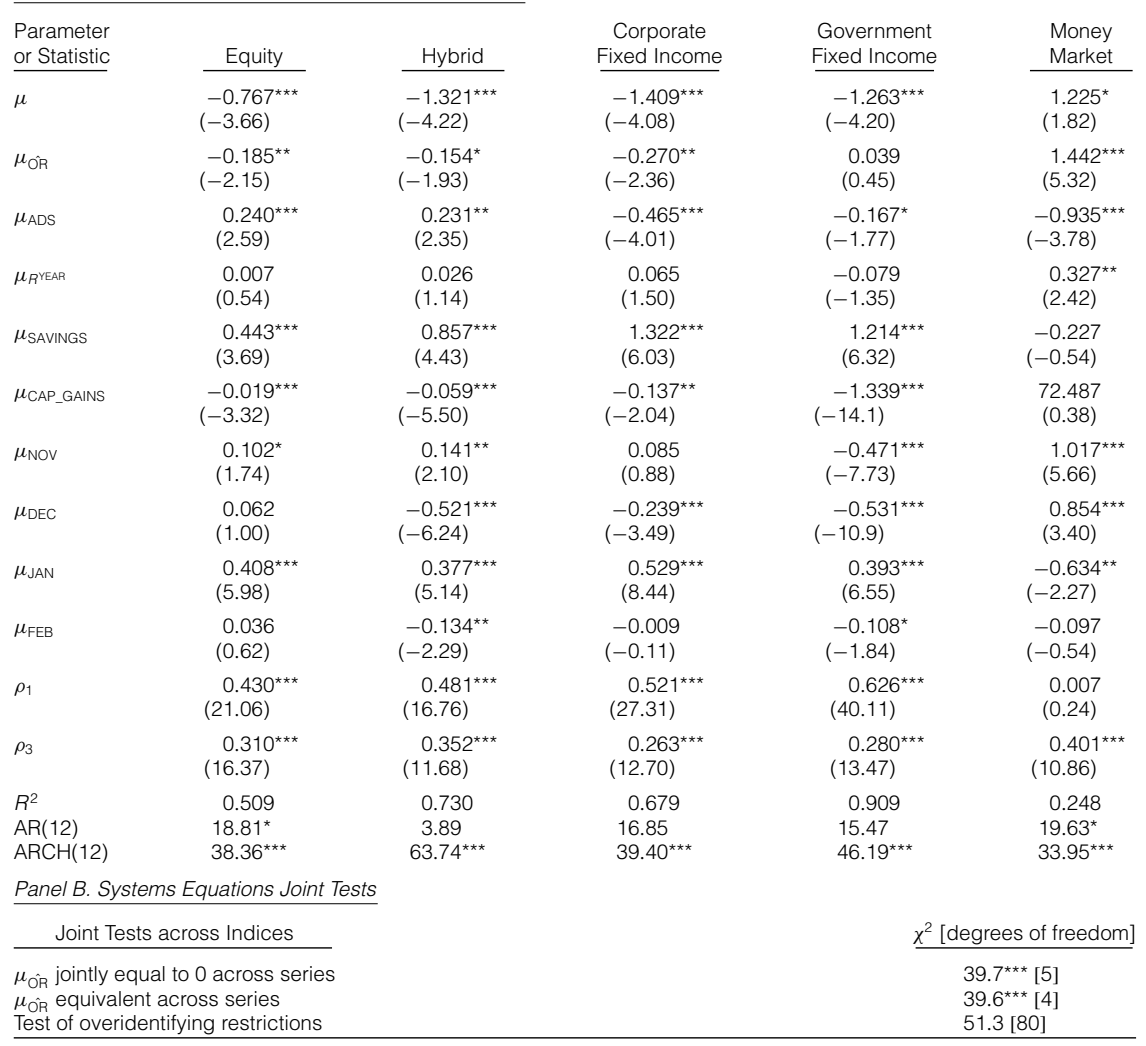


we present coefficient estimates and 2-sided $t$-tests. The bottom of Panel A contains the adjusted $R^{2}$ for each asset-class model and $\chi^{2}$ statistics for testing for the presence of up to 12 lags of autocorrelation or autoregressive conditional heteroskedasticity (ARCH) (see Engle (1982)).

Consider the coefficient estimates on the onset/recovery variable. The riskiest category, equities, has a statistically significant negative coefficient estimate; we discuss economic significance shortly. Recall that the onset/recovery variable itself is positive in the summer/fall and negative in the winter/spring (see Figure 1). Thus, the implication is that equity fund flows are expected to be below average in the summer/fall and above average in the winter/spring, consistent with the plot of unconditional equity fund flows shown in Figure 2. The onset/recovery coefficient estimate is positive and strongly statistically significant for the safest asset class, the money market category, implying that money market fund flows are expected to be above average in the summer/fall and below average in the winter/spring, again as we see unconditionally. Although we focus attention on the safest and riskiest categories of funds, we note that the intermediate-risk categories by measure of the CAPM beta estimate on fund category returns, the hybrid and corporate fund categories (see Table 2), also have negative coefficients. Further, government fixed income, which has a CAPM beta of approximately 0 and is, arguably, very nearly as safe as the money market funds (which invest in shorter-term Treasuries) has a positive but statistically insignificant coefficient estimate on $\hat{\mathrm{OR}}_{t}$. Although the signs and statistical significance of the three intermediate-risk fund categories are somewhat sensitive to the exact model specification, in particular, the inclusion or exclusion of dummy variables for November through February, the core result of opposing seasonalities in flows when considering the extremes of the fund categories (i.e., equity versus money market) is robust.

In Panel B of Table 3, we present statistics testing the joint significance of the onset/recovery coefficient estimates across the asset classes, using Wald $\chi^{2}$ statistics based on the HAC covariance estimates. The first statistic tests whether the onset/recovery estimates are jointly equal to 0 across the series. We strongly reject the null of no effect due to seasonally varying risk aversion. The second joint statistic tests whether the onset/recovery coefficient estimates are jointly equal to each other, not necessarily 0 . This null is strongly rejected as well, supporting the position that the safe and risky funds do indeed exhibit different seasonal cycles in flows related to the onset/recovery variable. We also provide a $\chi^{2}$ goodness-offit test of the model. ${ }^{27}$ The goodness-of-fit test indicates that the overidentifying moment restrictions we use to estimate the model are not rejected.

We now consider other coefficient estimates shown in Table 3. The advertising expenditure coefficient estimate is positive for the equity and hybrid classes, and it is strongly significantly negative for the remaining classes. This finding suggests that although fund-family advertising may attract flows to equity funds, it likely does so at the expense of relatively safer funds. The return over the previous year, $R^{\text {YEAR }}$, has a positive coefficient estimate for all asset classes except

\footnotetext{
${ }^{27}$ Hansen (1982) details conditions sufficient for consistency and asymptotic normality of GMM estimation and shows that the optimized value of the objective function produced by GMM is asymptotically distributed as $\chi^{2}$, providing a goodness-of-fit test of the model.
} 
for government fixed income, broadly consistent with flows chasing performance. Untabulated analysis confirms that the unconditional correlation of fund flows and lagged fund returns is strongly and statistically significant but that the inclusion of lagged fund flows attenuates this effect. The savings variable is strongly significantly positive for all classes of funds except the money market class, consistent with the notion that liquidity has an important impact on flows for most classes of funds. The capital-gains overhang coefficient estimate is negative for all classes except money market funds, which has an insignificant positive coefficient. (The magnitude of the coefficient estimate for the money market fund class is somewhat misleading because the average capital gains for this class of funds is virtually 0 , coming in at approximately a hundredth of a basis point. This results in a minuscule economic impact for the money market class, consistent with the statistical insignificance of its coefficient estimate.) These results on the capital-gains overhang coefficient estimate are broadly consistent with individual investors having a tendency to avoid purchasing funds that have substantial realized gains to distribute.

\section{Fit of the Net Flows Model}

Recall that the dotted lines with diamonds that appear in Figure 2 represent fitted values implied by the onset/recovery coefficient from estimating equation (1). It is also interesting to explore whether the full model can account for seasonalities only partially captured by the onset/recovery variable. In Figure 3, we plot the equity (Graph A) and money market (Graph B) monthly flows together with the average fitted values implied by the full model, indicated by a dashed line with diamonds.

\section{FIGURE 3}

Average Monthly U.S. Net Flows and Predicted Flows Due to Onset/Recovery from Full Model: Equity and Money Market

Graph A of Figure 3 contains monthly average equity asset-class fund net flows as a percentage of prior-month equity class TNA, indicated with a thick solid line, and average fitted values from estimating equation (1), indicated with a dashed line with diamonds. Graph B contains monthly average money market asset-class fund net flows as a percentage of prior-month money market TNA, indicated with a thick solid line, and average fitted values from estimating equation (1), indicated with a dashed line with diamonds. The plots also include a $90 \%$ confidence interval around the monthly means (shown with thin dashed lines) and the average flow throughout the year (represented by solid lines with circles and an $x$ mark in cases where the average return falls outside of the confidence interval). The data span Feb. 1985 through Dec. 2006.
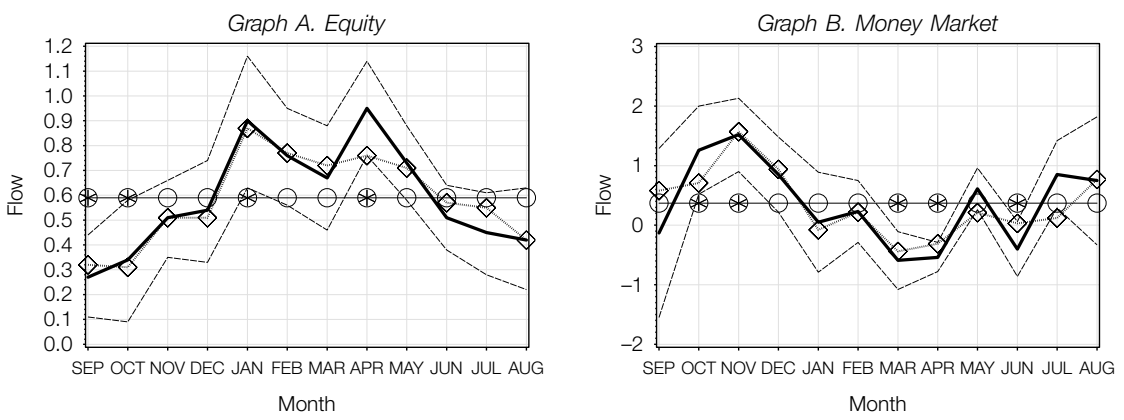
The full model, accounting for conditional effects and autocorrelation in flows, fits the unconditional seasonality in fund flows well. ${ }^{28}$ Indeed, analysis of the residuals from this model shows no remaining seasonality in equity or money market flows. The time-series fit of the models is shown in Figure 4. Note that we plot all available data, including data we do not use to estimate the models, 2007 and beyond. Graph A corresponds to the equity fund flows, and Graph B corresponds to money market fund flows. In each graph, a solid line represents the time series of flows as a percentage of TNA, and a dashed line with dots represents the fitted values from estimating equation (1). (In both graphs, a few observations lie outside the range of values plotted.) The fit of the model is less precise over the first few years of the sample, consistent with the very volatile equity markets during the late 1980s. The spikes in flows during this period mostly coincide with extreme market events, such as the October 1987 equity market crisis. In addition, in January 1990 the ICI implemented changes in its data-collection practices, an artifact of which is outliers in the flow and returns data in that year, and in general, the ICI data are likely less precise prior to $1996 .^{29}$ The flows corresponding to the hybrid, corporate bond, and government bond asset classes are very similar to the equity and money market asset classes and are not presented. Generally, these models are able to match the data well, in particular, the seasonal periodicity (a feature most obvious in the money market asset class). In terms of $R^{2}$, there is substantial variation in fit across categories, with the government bond fund class showing an $R^{2}$ of approximately $90 \%$ and the money market fund class being the most difficult to fit with an $R^{2}$ of approximately $25 \%$.

\section{FIGURE 4}

\section{Time Series of U.S. Net Flows}

Graph A of Figure 4 contains the time series of monthly equity fund net flows as a percentage of prior-month equity class TNA, indicated with a solid line, and the monthly fitted values from estimating equation (1), indicated with dots and a dashed line. Graph B contains the time series of monthly money market fund net flows as a percentage of prior-month money market class TNA, indicated with a solid line, and the monthly fitted values from estimating equation (1), indicated with a dashed line. The data span Jan. 1984 through Dec. 2009. The model is estimated over the period 1985-2006; hence, the fitted series starts later and ends earlier than the realized series in the plot.
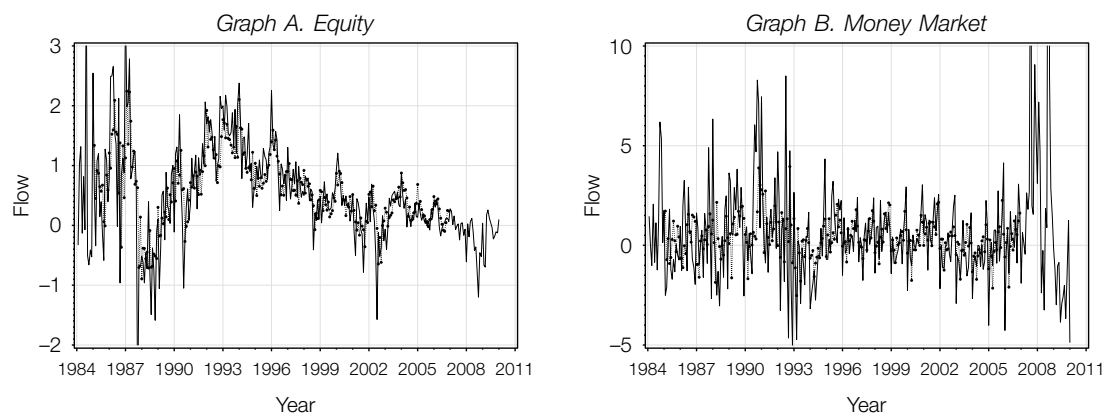

\footnotetext{
${ }^{28}$ The lack of a perfect fit in the months for which we include dummy variables (November, December, January, and February) is due to our use of GMM instead of a least squares method.

${ }^{29}$ The ICI informed us that it reorganized categories in 1996 and that the precision of ICI flow estimates improved afterward.
} 
As a robustness check, balancing the need for a long period of time to estimate the model and concern for the quality of the early data period, we estimate equation (1) after having truncated pre-1991 data from the sample. We find (in untabulated results) that the results for the impact of the onset/recovery variable are qualitatively unchanged, although the magnitude and significance are somewhat reduced. Exploring the 2000-2010 period shows very similar results to those found for the 1985-2006 period.

\section{Investor Sentiment and Mutual Fund Flows: Net Exchanges}

Ben-Rephael et al. (2012) also explore flows between fund categories, finding that monthly shifts between bond funds and equity funds in the United States are related to aggregate equity market excess return movements. The flows they consider are net exchanges (exchanges in minus exchanges out), in contrast to the net flows (net exchanges plus sales net of redemptions) typically considered in the fund flows literature and used to this point in our own exploration of seasonality in flows. Ben-Rephael et al. (2012) suggest that net exchanges reflect the asset-allocation decisions of fund investors, in contrast to sales net of redemptions, which incorporate long-term savings, withdrawals, and short-term liquidity needs. If seasonally varying risk aversion indeed impacts household asset-allocation decisions, then a clear implication of Ben-Rephael et al.'s (2012) claim is that this impact should be evident in net exchanges.

The regression model we estimate for net exchanges is as follows:

$$
\begin{aligned}
& \text { NET_EXCHANGE } i, t=\mu_{i}+\mu_{i, \hat{\mathrm{OR}}} \hat{\mathrm{OR}}_{t}+\mu_{i, \mathrm{ADS}} \mathrm{ADS}_{t}+\mu_{i, R} \mathrm{YEAR} R_{i, t}^{\mathrm{YEAR}} \\
& +\mu_{i, \text { CAP_GAINS }} R_{i, t}^{\text {CAP_GAINS }}+\rho_{i, 1} \text { NET_EXCHANGE }{ }_{i, t-1} \\
& +\rho_{i, 3} \text { NET_EXCHANGE }{ }_{i, t-3}+\epsilon_{i, t} \text {, }
\end{aligned}
$$

where $i$ references the asset class. The dependent variable, NET_EXCHANGE EX $_{i, t}$, is the month $t$ net exchange expressed as a percentage of month $t-1$ total net assets, and the remaining variables are as previously defined. In this model, we exclude personal savings because exchanges between funds should be invariant to this quantity; indeed, a point of looking at net exchanges is to expunge the impact of savings directly rather than simply to control for it in the regression model. We do not include dummy variables for the months of November through February in this model because the motivation for these dummies is lacking for net exchanges. That is, we already control for capital gains, and furthermore, the other flow seasonalities that the dummy variables might be helpful for controlling (the reinvestment of dividend and capital-gains distributions from mutual funds that concentrate around the year-end and flows from variable compensation such as year-end bonuses) should not impact net exchanges. Nonetheless, in Internet Appendix Section A-1, we provide a robustness check confirming that the inclusion/exclusion of these dummy variables does not qualitatively change the results.

We estimate equation (2) as a system of equations using Hansen's (1982) GMM and Newey and West (1987), (1994) HAC standard errors. Table 4 contains estimation results. Similar to the results presented for net flows, the $\hat{\mathrm{OR}}_{t}$ estimated coefficients for net exchanges are significantly negative for the riskiest asset class, equities, and significantly positive for the safest class, the money 
TABLE 4

Regression Results for U.S. Asset-Class Net Exchanges

In Table 4, we report coefficient estimates from jointly estimating the following regression for each of the U.S. asset classes in a GMM framework:

(2)

$$
\begin{aligned}
& \mathrm{NET}_{-} \mathrm{EXCHANGE}{ }_{i, t}=\mu_{i}+\mu_{i, \hat{\mathrm{OR}}} \hat{\mathrm{OR}}_{t}+\mu_{i, \mathrm{ADS}} \mathrm{ADS}_{t}+\mu_{i, R^{\mathrm{YEAR}}} R_{i, t}^{\mathrm{YEAR}} \\
& +\mu_{i, \text { CAP_GAINS }} R_{i, t}^{\text {CAP_GAINS }}+\rho_{i, 1} \text { NET_EXCHANGE } i, t-1 \\
& +\rho_{i, 3} \mathrm{NET}_{-} \text {EXCHANGE }{ }_{i, t-3}+\epsilon_{i, t} \text {, }
\end{aligned}
$$

The data used to estimate the model span Feb. 1985 through Dec. 2006. The monthly net exchanges are computed as exchanges in minus exchanges out. The dependent variable is monthly fund net exchanges as a percentage of the previous month's TNA. The explanatory variables are defined in the text. In Panel A, we present coefficient estimates with HAC robust $t$-tests (reported in parentheses) and the value of adjusted $R^{2}$ for each estimation, a Wald $\chi^{2}$ test statistic for the presence of up to 12 lags of autocorrelation (AR), and a Wald $\chi^{2}$ test statistic for the presence of up to 12 lags of $\mathrm{ARCH}$ (both with 12 degrees of freedom). The test for ARCH is a standard LM test of order 12. See Engle (1982). To perform the test for autocorrelation, we augment the regression with 12 lags of the residuals, estimate MacKinnon and White (1985) bootstrap heteroskedasticity-consistent standard errors with OLS, and test for the joint significance of these terms. Panel B contains joint test statistics. The first is a $\chi^{2}$ statistic (with 5 degrees of freedom) testing the null that the onset/recovery coefficient estimates are jointly 0 across the fund asset classes, the second is a $\chi^{2}$ statistic (with 4 degrees of freedom) testing the null that the onset/recovery coefficient estimates are jointly equal to each other across the asset classes, and the third is the Hansen (1982) $\chi^{2}$ goodness-of-fit test of the model based on the optimized value of the objective function produced by GMM. To calculate the standard errors, we follow Newey and West (1987), (1994) and use the Bartlett kernel and an automatic bandwidth parameter (autocovariance lags) equal to the integer value of $4(T / 100)^{2 / 9}$. We use the full set of explanatory variables as instruments for the regression. *, ${ }^{* *}$, and ${ }^{* * *}$ indicate

\begin{tabular}{|c|c|c|c|c|c|}
\hline Parameter & Equity & Hybrid & Corp. Bond & Gov. Bond & MMkt \\
\hline$\mu$ & $\begin{array}{l}0.109^{\star \star *} \\
(2.73)\end{array}$ & $\begin{array}{c}0.024 \\
(1.08)\end{array}$ & $\begin{array}{l}0.306^{\star \star \star} \\
(5.91)\end{array}$ & $\begin{array}{l}0.131^{* \star \star} \\
(2.76)\end{array}$ & $\begin{array}{l}-0.137^{\text {** }} \\
(-3.84)\end{array}$ \\
\hline$\mu_{\mathrm{OR}}$ & $\begin{array}{l}-0.152^{\star \star \star} \\
(-4.29)\end{array}$ & $\begin{array}{c}0.010 \\
(0.62)\end{array}$ & $\begin{array}{l}-0.106^{\star \star} \\
(-1.97)\end{array}$ & $\begin{array}{l}0.105^{\star \star \star} \\
(3.08)\end{array}$ & $\begin{array}{l}0.212^{\star \star \star} \\
(4.72)\end{array}$ \\
\hline$\mu_{\mathrm{ADS}}$ & $\begin{array}{l}-0.086^{\star \star} \\
(-2.12)\end{array}$ & $\begin{array}{l}-0.009 \\
(-0.44)\end{array}$ & $\begin{array}{l}-0.308^{\star \star \star} \\
(-6.37)\end{array}$ & $\begin{array}{l}-0.131^{\star \star \star} \\
(-2.99)\end{array}$ & $\begin{array}{l}0.168^{\star \star \star} \\
(4.58)\end{array}$ \\
\hline$\mu_{R_{Y E A R}}$ & $\begin{array}{l}-0.001 \\
(-0.32)\end{array}$ & $\begin{array}{l}-0.014^{\star \star \star} \\
(-3.86)\end{array}$ & $\begin{array}{l}0.045^{\star \star \star} \\
(2.58)\end{array}$ & $\begin{array}{l}0.075^{\star \star \star} \\
(4.27)\end{array}$ & $\begin{array}{l}0.029 * * \\
(2.42)\end{array}$ \\
\hline$\mu_{\text {CAP_GAINS }}$ & $\begin{array}{l}-0.015^{\star \star \star} \\
(-8.32)\end{array}$ & $\begin{array}{l}-0.006^{\star \star \star} \\
(-3.02)\end{array}$ & $\begin{array}{l}-0.110^{\star \star \star} \\
(-5.55)\end{array}$ & $\begin{array}{l}-0.414^{* * *} \\
(-13.2)\end{array}$ & $\begin{array}{l}-22.21^{\star \star \star} \\
(-4.33)\end{array}$ \\
\hline$\rho_{1}$ & $\begin{array}{l}0.050^{\star \star \star} \\
(2.89)\end{array}$ & $\begin{array}{c}0.620^{\star \star \star} \\
(24.44)\end{array}$ & $\begin{array}{l}0.200^{\star \star \star} \\
(8.72)\end{array}$ & $\begin{array}{l}0.198^{\star \star \star} \\
(9.37)\end{array}$ & $\begin{array}{c}0.190^{\star \star \star} \\
(10.12)\end{array}$ \\
\hline$\rho_{3}$ & $\begin{array}{c}0.156^{\star \star *} \\
(10.48)\end{array}$ & $\begin{array}{l}0.224^{\star \star \star} \\
(8.56)\end{array}$ & $\begin{array}{l}0.057^{\star \star \star *} \\
(2.76)\end{array}$ & $\begin{array}{l}-0.020 \\
(-0.94)\end{array}$ & $\begin{array}{l}0.070^{* \star \star} \\
(4.99)\end{array}$ \\
\hline $\begin{array}{l}R^{2} \\
\mathrm{AR}(12) \\
\mathrm{ARCH}(12)\end{array}$ & $\begin{array}{l}0.0731 \\
10.40 \\
11.73\end{array}$ & $\begin{array}{l}0.6315 \\
9.08 \\
17.94\end{array}$ & $\begin{array}{l}0.0876 \\
18.86^{*} \\
18.26\end{array}$ & $\begin{array}{l}0.1892 \\
8.70 \\
18.20\end{array}$ & $\begin{array}{l}0.0667 \\
16.07 \\
36.18^{\star \star \star}\end{array}$ \\
\hline \multicolumn{6}{|c|}{ Panel B. Systems Equations Joint Tests } \\
\hline \multicolumn{2}{|c|}{ Joint Tests across Indices } & & & \multicolumn{2}{|c|}{$\underline{\chi^{2}[\text { degrees of freedom] }}$} \\
\hline \multicolumn{3}{|c|}{$\begin{array}{l}\mu_{\mathrm{OR}} \text { jointly equal to } 0 \text { across series } \\
\mu_{\hat{\mathrm{OR}}} \text { equivalent across series } \\
\text { Test of overidentifying restrictions }\end{array}$} & & \multicolumn{2}{|c|}{$\begin{array}{l}61.3^{\star \star \star}[5] \\
41.4^{\star \star \star}[4] \\
50.5[80]\end{array}$} \\
\hline
\end{tabular}
significance at the $10 \%, 5 \%$, and $1 \%$ levels, respectively, based on 2 -sided tests.

Panel A. Parameter Estimates and Diagnostic Statistics

market. Just as we saw earlier, the money market class displays the largest magnitude onset/recovery effect. For the three categories between the safest and riskiest extremes, we see a mix of positive and negative coefficient estimates, with the estimate insignificant for the hybrid class. The magnitudes of the coefficient estimates on the intermediate-risk categories lie between the values for the equity and money market categories. In terms of $R^{2}$, there is again substantial variation in fit across categories with uniformly smaller $R^{2}$ values for net exchanges than for flows, most notably for the money market category. The hybrid fund category flows are the most easily fit with an $R^{2}$ of approximately $60 \%$, and the money market fund class is the most difficult to fit with an $R^{2}$ below $7 \%$. 
The statistics in Panel B of Table 4 reveal that the onset/recovery estimates are jointly statistically different from 0 and different from each other across asset classes, again strongly rejecting the null of no seasonal-depression-related effect. The goodness-of-fit test indicates that the overidentifying moment restrictions we use to estimate the model are not rejected.

\section{E. Economic Magnitude}

One way to assess the economic impact of the influence of seasonally varying risk aversion on flows and exchanges is directly from the OR coefficient estimates. For example, in Table 3 (based on net flows), the ÔR coefficient estimate is approximately 1.4 for the money market class. To calculate economic impact, we multiply 1.4 by the value of the onset/recovery variable for a given month. In September, onset/recovery equals 38\% (as reported in Section III). Thus, the average economic impact of seasonally varying risk aversion on money market fund flows in September is $0.52 \%$ of the previous month's total net assets of the taxable government money market class.

Another way to evaluate the economic magnitude is by examining the percentage of the seasonal variation, from the fall trough to the spring peak, captured by the onset/recovery variable. For the U.S. equity mutual funds in Figure 2, realized flows reach a trough of approximately 0.25 (as a proportion of prior-month TNA) in the fall and reach a peak of approximately 0.95 in the spring. In comparison, the fitted value based on the onset/recovery variable troughs at approximately 0.5 and peaks at approximately 0.65 . Thus, for U.S. equity fund flows, the variation in the fitted value accounts for approximately $20 \%$ of the seasonal variation in the realized series. For U.S. money market flows, the fitted value accounts for approximately $50 \%$ of the seasonal variation.

Yet another way to assess the economic magnitude is by calculating the actual dollar flows associated with the impact of seasonally varying risk aversion. For example, in Sept. 2004, the TNA of the taxable government money market class was $\$ 353$ billion. Multiplying that value by the $0.52 \%$ of TNA we calculated previously yields an onset/recovery-associated economic impact of approximately $\$ 1.5$ billion flowing into the money market asset class in Sept. 2004. In the spring, the economic impact was such that approximately $\$ 1.8$ billion flowed out of money market funds in Mar. 2005. These are immediate impacts (not accounting for the autocorrelation in the flows) and thus understate the impact. Accounting for autocorrelation leads to a total impact closer to \$3-4 billion, ${ }^{30}$ summarizing the economic impact on net flows and exchanges (accounting for autocorrelation) for all five asset classes, for 2006.

Each line in Figure 5 represents the average monthly economic magnitude of the seasonally varying risk-aversion effect for a given fund. The thickest dashed line corresponds to the money market. Our estimated models for the impact of onset and recovery suggest that seasonally varying risk aversion reduces net flows to equity funds by approximately $\$ 13$ billion (circa 2006) and increases flows to

\footnotetext{
${ }^{30}$ To calculate the total monthly impact in the setting of a model with autoregressive terms, we divide the immediate impact by 1 minus the sum of the autoregressive coefficients. In the case of money market flows, we can see from Table 3 that this amounts to multiplying by roughly 2.5 . We plot the total monthly impact in Figure 5.
} 
FIGURE 5

U.S. Flows Attributed to Seasonally Varying Risk Aversion

Figure 5 contains the monthly net flows and net exchanges due to onset/recovery, in billions of dollars, by fund asset class, for 2006. The legend indicates which lines represent which classes. Graph A presents total net flows predicted from equation (1) as arising from onset/recovery, and Graph B presents total net exchanges predicted from equation (2) as arising from onset/recovery.
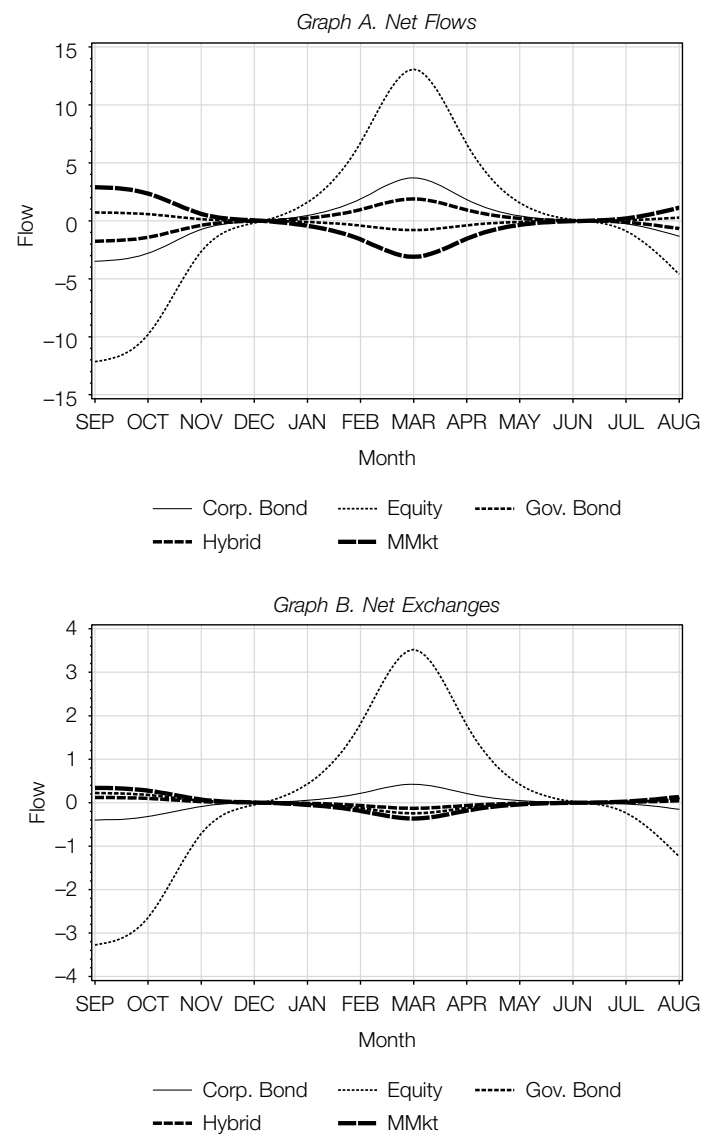

money market funds by roughly $\$ 3-4$ billion, on average, during the fall month of September, reversing in the spring month of March. Net exchanges are approximately $25 \%$ as large as net flows. Other asset classes exhibit less extreme flows due to seasonally varying risk aversion than the riskiest and safest fund categories. $^{31}$

If we aggregate the economic magnitudes across all categories for a given month in Figure 5, it is apparent that the onset/recovery-associated mutual fund flows do not net out, even approximately, to 0 across the categories. When aggregated across all fund categories, the net flows attributable to onset/recovery

\footnotetext{
${ }^{31}$ Robustness checks with a model excluding autoregressive terms confirm the rough magnitudes of these economic effects; see Internet Appendix Section A-6.
} 
indicate that net outflows in the fall and net inflows in the winter (aggregated across asset classes) are at maximum approximately $\$ 10$ billion per month in September and March, roughly $\$ 5$ billion in October and February, and roughly $\$ 2$ billion in November and January, respectively. This works out to approximately $\$ 6$ billion in average monthly outflows in the fall months and $\$ 6$ billion in average monthly inflows in the spring months and raises the question, is there some other counterbalancing category of savings to/from which funds flow? The largest savings category is, perhaps, bank accounts, including checking, savings, and money market accounts (separate and distinct from money market mutual funds).

To answer this question, in an untabulated analysis, we consider deposit data (adjusted for inflation but unadjusted for seasonality) provided by the Board of Governors of the Federal Reserve System. ${ }^{32}$ We find that bank accounts do indeed have inflows and outflows that match the direction of money market fund flows: inflows in the fall and outflows in the winter. The monthly winter outflows are just over $\$ 4$ billion per month on average, a reasonable match to the estimate for the unaccounted-for winter fund outflows, but the fall bank account inflows are large, at roughly $\$ 19$ billion per month on average, much larger than the unaccountedfor inflows of $\$ 6$ billion. Some of these flows are likely an artifact of individuals saving in advance of holiday spending, and saving does peak late in the quarter. If we leave out the December buildup in deposits, we have an average monthly flow of approximately $\$ 10$ billion, a closer match to the unaccounted-for fall fund outflows.

\section{Canadian and Australian Flows}

Seasonal light exposure, of course, varies by location. Countries located at more extreme northern latitudes experience less daylight in the fall and winter relative to the United States, and countries located in the southern hemisphere experience seasons offset by 6 months relative to the United States. We use these differences to perform robustness tests. Seasonal variation in flows due to seasonally varying investor sentiment ought to be more extreme in countries located at more northern latitudes, such as Canada, and should be offset by 6 months in southern hemisphere countries, such as Australia. ${ }^{33}$

\section{A. Canadian Flows}

The majority of Canada's population resides at latitudes north of the United States, and thus experiences relatively more extreme seasonal fluctuations of

\footnotetext{
${ }^{32}$ We obtained seasonally unadjusted total savings deposits and demand deposits plus other checkable deposits from the St. Louis Federal Reserve Bank, series IDs SAVINGNS and TCDNS, respectively, deflated with CPIAUCNS (the consumer price index for all urban consumers, seasonally unadjusted, from the U.S. Department of Labor, Bureau of Labor Statistics).

${ }^{33}$ Because Canada and the United States have identical tax years and because the Australian tax year is offset by 6 months, we cannot fully eliminate the possibility that legal or institution factors contribute to the seasonal effects we document. When suitably long and rich time-series data from a broader set of countries become available and as suitable data from different latitudes within a country such as the United States become available, more refined cross-sectional tests will become feasible. We leave this exploration for future research.
} 
daylight. ${ }^{34}$ If the seasonally varying risk-aversion hypothesis is correct, Canadian flows should exhibit relatively more exaggerated seasonality. The Investment Funds Institute of Canada (IFIC) provided Canadian fund flow data that are similar to the previously described ICI data for the United States. The IFIC data were provided in 10 categories of funds, which we converted into four broad categories: equity, hybrid, fixed income, and global fixed income. Internet Appendix Section A-7 contains details on the Canadian data, including information about the construction of the four categories (Table A-7.1), summary statistics on the net exchange data (Table A-7.2), and plots of the monthly average mean flows for equity and fixed-income funds.

We focus on net exchanges rather than net flows for Canada because net flows are heavily impacted by the peculiarities of Canadian tax law regarding tax-shielded and deductible retirement savings, known as registered retirement savings plans (RRSPs). Although analogous to U.S. 401(k)s, the Canadian RRSP deadline for eligible contributions is Mar. 1 of the calendar year following the Dec. 31 end of the tax year, with Canadian financial institutions running intensive marketing campaigns encouraging RRSP contributions during January and especially February. This leads to very sharp increases in net flows into all fund categories in the first 3 months of the calendar year. The Canadian net flows pattern peaks in February, with substantial contributions to RRSPs extending even to the last eligible day for contributions, Mar. 1, which impacts March flows as well. For every Canadian fund category we study, January, February, and March flows dominate the year, making it challenging to distinguish flow patterns over this period that are unrelated to a tax-year effect. Although autumn patterns in Canadian net flows data are consistent with seasonally varying risk aversion (flows into safe funds and out of risky funds, on average), we turn to Canadian net exchanges to formally evaluate seasonalities without the complications induced by Canadian retirement savings legislation.

The range of the Canadian data extends from Jan. 1992 through Nov. 2010. (The need for lagged values restricts the estimation period to start in Jan. 1993.) As with the U.S. data, concerns about the chaotic flows during the financial crisis, in particular, flows in and out of money market funds, compel us to end the sample in Dec. 2006 for the purposes of model estimation.

The regression model we consider is as follows:

$$
\begin{aligned}
& \mathrm{NET}_{\mathrm{N}} \mathrm{EXCHANGE} i, t=\mu_{i}+\mu_{i, \hat{\mathrm{OR}}} \hat{\mathrm{OR}}_{t}+\mu_{i, R} \mathrm{YEAR} R_{i, t}^{\mathrm{YEAR}} \\
& +\mu_{i, \text { CAP_GAINS }} R_{i, t}^{\text {CAP_GAINS }}+\rho_{i, 1} \text { NET_EXCHANGE }_{i, t-1} \\
& +\rho_{i, 3} \mathrm{NET}_{\text {EXCHANGE }}, t,-3+\rho_{i, 6} \mathrm{NET}_{\text {EXCHANGE }} \mathrm{EXC}_{i, 6} \\
& +\epsilon_{i, t} \text {, }
\end{aligned}
$$

where $i$ references the mutual fund asset class. The monthly net exchanges are computed as exchanges in minus exchanges out. The dependent variable is monthly fund net exchanges as a percentage of the previous month's TNA.

\footnotetext{
${ }^{34}$ The U.S. population centroid (mean center) is approximately 37 degrees north (U.S. Census Bureau, based on the 2000 census), whereas the Canadian population centroid is approximately 48 degrees north. See Kumler and Goodchild (1992).
} 
$\hat{\mathrm{OR}}_{t}$ is the onset/recovery variable. Unfortunately, we were not able to obtain Canadian-fund-family advertising data; the remaining explanatory variables are as follows: $R_{i, t}^{\mathrm{YEAR}}$ is the return to fund asset class $i$ over the prior 12 months (i.e., from month $t-13$ through to month $t-1$ ), included to control for returnchasing exchanges. ${ }^{35} R_{i, t}^{\text {CAP_GAINS }}$ is included to control for the influence of capitalgains overhang on exchanges, calculated as the cumulated return to holding the fund from the previous year's Jan. 1 (the start of the tax year in Canada) until month $t-1$. Unlike in the United States, mutual funds in Canada did not face the U.S. Tax Reform Act of 1986, and tax reporting on capital gains follows the tax year, January through December. ${ }^{36}$ Hence, $R_{i, t}^{\text {CAP_GAINS }}$ equals the cumulated return to holding the fund from the start of the tax year until month $t-1$. In modeling Canadian net exchanges, we do not include dummy variables for the months of November through February, just as we did not include them for U.S. exchanges. (Recall that the motivation for including the monthly dummies is lacking for net exchanges; capital gains are controlled for directly, and net exchanges are unaffected by reinvestment seasonalities and year-end bonuses, the latter of which are relatively less common in Canada in any case.) Nonetheless, in Internet Appendix Section A-7, we provide a robustness check confirming that the findings do not depend on the inclusion/exclusion of these dummy variables. In an untabulated analysis, we also find that the results are qualitatively invariant to how we control for autocorrelation.

We estimate equation (3) as a system of equations using Hansen's (1982) GMM and Newey and West (1987), (1994) HAC standard errors. ${ }^{37}$ Table 5 contains estimation results. Consider, first, the coefficient estimates on the onset/recovery variable. The equity and hybrid asset classes both have negative and statistically significant $\hat{\mathrm{OR}}_{t}$ coefficients. Recall that the onset/recovery variable itself is positive in the summer/fall and negative in the winter/spring (see Figure 1). Thus, the implication is that equity fund exchanges are expected to be below average in the summer/fall and above average in the winter/spring, as displayed in the plot in Figure A-7.1. The onset/recovery coefficient estimate is positive and statistically significant for both of the fixed-income asset classes, implying that fixed-income fund exchanges are expected to be above average in the summer/fall and below average in the winter/spring, again as we see unconditionally.

It is interesting to compare the magnitude of the coefficient estimates on the onset/recovery variable for Canadian and U.S. fund exchanges. One way to

\footnotetext{
${ }^{35}$ The month $t$ return for asset class $i$ is calculated as $R_{i, t}=\left(\mathrm{TNA}_{i, t}-\mathrm{TNA}_{i, t-1}\right.$ - NET_FLOW $\left.{ }_{i, t}\right) / \mathrm{TNA}_{i, t-1}$, which assumes that all distributions are reinvested in the funds.

${ }^{36}$ Recall that for the United States, the primary capital-gains variable measures gains starting from November, consistent with the Oct. 31 tax year-end for mutual funds in the United States. Because the start of the Canadian tax year is Jan. 1, there is no analogous 2-month overhang period in Canada. Thus, for Canada, the capital-gains variable takes on nonzero values for all months of the year except January (the value is 0 in January by construction). We do not have access to Canadian realized capital gains, and so we are restricted to analysis based on this returns-based proxy for capital gains. The findings for Canada are robust to excluding the capital-gains variable from the model.

${ }^{37}$ To calculate standard errors, we follow Newey and West (1987), (1994) and use the Bartlett kernel and an automatic bandwidth parameter (autocovariance lags) equal to the integer value of $4(T / 100)^{2 / 9}$. The instruments are the full set of explanatory variables. Specifically, for each equation we include $\hat{\mathrm{OR}}_{t} ; \operatorname{lags} 1,3$, and 6 of the dependent variable; $R_{i, t}^{\mathrm{YEAR}}$; and $R_{i, t}^{\text {CAP_GAINS }}$.
} 
TABLE 5

\section{Regression Results for Canadian Asset-Class Net Exchanges}

In Table 5, we report coefficient estimates from jointly estimating the following regression for each of the asset classes in a GMM framework based on Canadian data:

$$
\begin{aligned}
\text { NET_EXCHANGE }_{i, t}= & \mu_{i}+\mu_{i, \hat{\mathrm{OR}}} \hat{\mathrm{OR}}_{t}+\mu_{i, R^{\mathrm{YEAR}}} R_{i, t}^{\mathrm{YEAR}} \\
& +\mu_{i, \mathrm{CAP}_{-} \mathrm{GAINS}} R_{i, t}^{\mathrm{CAP}_{\text {GAINS }}}+\rho_{i, 1} \mathrm{NET}_{-} \mathrm{EXCHANGE}_{i, t-1} \\
& +\rho_{i, 3} \mathrm{NET}_{i} \mathrm{EXCHANGE}_{i, t-3}+\rho_{i, 6} \mathrm{NET}_{-} \mathrm{EXCHANGE}_{i, t-6} \\
& +\epsilon_{i, t},
\end{aligned}
$$

The data used to estimate the model span Jan. 1993 through Dec. 2006. The monthly net exchanges are computed as exchanges in minus exchanges out. The dependent variable is monthly fund net exchanges as a percentage of the previous month's TNA. The explanatory variables are defined in the text. In Panel A, we present coefficient estimates with HAC robust $t$-tests (reported in parentheses) and the value of adjusted $R^{2}$ for each estimation, a Wald $\chi^{2}$ test statistic for the presence of up to 12 lags of autocorrelation (AR), and a Wald $\chi^{2}$ test statistic for the presence of up to 12 lags of $\mathrm{ARCH}$ (both with 12 degrees of freedom). The test for ARCH is a standard LM test of order 12. See Engle (1982). To perform the test for autocorrelation, we augment the regression with 12 lags of the residuals, estimate MacKinnon and White (1985) bootstrap heteroskedasticity-consistent standard errors with OLS, and test for the joint significance of these terms. Panel B contains joint test statistics. The first is a $\chi^{2}$ statistic (with 4 degrees of freedom) testing the null that the onset/recovery coefficient estimates are jointly 0 across the fund asset classes, the second is a $\chi^{2}$ statistic (with 3 degrees of freedom) testing the null that the onset/recovery coefficient estimates are jointly equal to each other across the asset classes, and the third is the Hansen (1982) $\chi^{2}$ goodness-of-fit test of the model based on the optimized value of the objective function produced by GMM. To calculate the standard errors, we follow Newey and West (1987), (1994) and use the Bartlett kernel and an automatic bandwidth parameter (autocovariance lags) equal to the integer

\begin{tabular}{|c|c|c|c|c|}
\hline $\begin{array}{l}\text { Parameter } \\
\text { or Statistic } \\
\end{array}$ & Equity & Hybrid & $\begin{array}{c}\text { Global } \\
\text { Fixed Income } \\
\end{array}$ & Fixed Income \\
\hline$\mu$ & $\begin{array}{c}0.006 \\
(0.68)\end{array}$ & $\begin{array}{l}-0.016^{\star \star} \\
(-2.00)\end{array}$ & $\begin{array}{l}-0.219^{\star \star \star} \\
(-5.65)\end{array}$ & $\begin{array}{l}-0.110^{\star \star \star} \\
(-5.73)\end{array}$ \\
\hline$\mu_{\mathrm{OR}}$ & $\begin{array}{l}-0.093^{* *} \\
(-2.07)\end{array}$ & $\begin{array}{l}-0.180^{\star \star \star} \\
(-4.24)\end{array}$ & $\begin{array}{l}0.338^{\star \star} \\
(2.23)\end{array}$ & $\begin{array}{l}0.270^{\star * \star} \\
(2.80)\end{array}$ \\
\hline$\mu_{R_{\mathrm{YEAR}}}$ & $\begin{array}{l}0.032^{* * *} \\
(4.16)\end{array}$ & $\begin{array}{l}0.049^{\star \star \star} \\
(3.20)\end{array}$ & $\begin{array}{l}-0.053 \\
(-1.27)\end{array}$ & $\begin{array}{l}0.098^{*} \\
(1.86)\end{array}$ \\
\hline$\mu_{\text {CAP_GAINS }}$ & $\begin{array}{l}-0.001 \\
(-1.36)\end{array}$ & $\begin{array}{l}-0.001 \\
(-0.59)\end{array}$ & $\begin{array}{c}0.006 \\
(1.51)\end{array}$ & $\begin{array}{l}-0.011^{\star *} \\
(-2.30)\end{array}$ \\
\hline$\rho_{1}$ & $\begin{array}{l}0.228^{\star \star \star} \\
(6.86)\end{array}$ & $\begin{array}{l}0.440^{\star \star \star} \\
(9.23)\end{array}$ & $\begin{array}{l}0.229^{\star \star \star} \\
(9.05)\end{array}$ & $\begin{array}{l}0.278^{* * \star} \\
(8.21)\end{array}$ \\
\hline$\rho_{3}$ & $\begin{array}{l}0.053^{* * \star} \\
(2.76)\end{array}$ & $\begin{array}{l}0.179^{\star \star \star} \\
(5.81)\end{array}$ & $\begin{array}{l}0.061^{\star \star \star} \\
(3.34)\end{array}$ & $\begin{array}{l}0.066^{* * *} \\
(2.81)\end{array}$ \\
\hline$\rho_{6}$ & $\begin{array}{c}0.033 \\
(1.50)\end{array}$ & $\begin{array}{l}0.070^{\star \star \star} \\
(3.99)\end{array}$ & $\begin{array}{c}0.040 \\
(1.55)\end{array}$ & $\begin{array}{l}0.071^{\star * \star} \\
(2.86)\end{array}$ \\
\hline $\begin{array}{l}R^{2} \\
\mathrm{AR}(12) \\
\mathrm{ARCH}(12)\end{array}$ & $\begin{array}{l}0.0759 \\
13.98 \\
14.90\end{array}$ & $\begin{array}{c}0.3832 \\
25.64^{\star \star} \\
38.77^{\star \star \star}\end{array}$ & 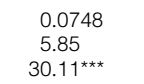 & $\begin{array}{l}0.1076 \\
19.05^{\star} \\
9.01\end{array}$ \\
\hline \multicolumn{5}{|c|}{ Panel B. Systems Equations Joint Tests } \\
\hline \multicolumn{2}{|c|}{ Joint Tests across Indices } & & \multicolumn{2}{|r|}{$\underline{\chi^{2}[\text { degrees of freedom] }}$} \\
\hline \multicolumn{2}{|c|}{$\begin{array}{l}\mu_{\mathrm{OR}} \text { jointly equal to } 0 \text { across series } \\
\mu_{\hat{O} \mathrm{R}} \text { equivalent across series } \\
\text { Test of overidentifying restrictions }\end{array}$} & & \multicolumn{2}{|r|}{$\begin{array}{l}24.9^{\star \star \star}[4] \\
22.9^{\star \star \star}[3] \\
33.2[60]\end{array}$} \\
\hline
\end{tabular}
value of $4(T / 100)^{2 / 9}$. We use the full set of explanatory variables as instruments for the regression. ${ }^{*},{ }^{* *}$, and ${ }^{* * *}$ indicate significance at the $10 \%, 5 \%$, and $1 \%$ levels, respectively, based on 2 -sided tests.

Panel A. Parameter Estimates and Diagnostic Statistics

identify the seasonally varying risk-aversion effect, distinct from other seasonal influences, is to consider an implication of the hypothesis that net exchanges should be more pronounced the further the market is away from the equator, consistent with the clinical observation by Magnusson (2000) and others that the prevalence of seasonal depression generally increases with distance from the equator. The average $\hat{\mathrm{OR}}_{t}$ value across the U.S. equity and hybrid fund class net exchanges (based on values in Table 4) is approximately -0.08 , whereas the average onset/recovery coefficient across the Canadian equity and hybrid fund classes 
net exchanges is approximately -0.14 (based on the values in Table 5). The U.S. government bond and money market fund class net exchanges onset/recovery coefficient is approximately 0.16 (again based on the values in Table 4) compared with the Canadian bond and global bond fund class net exchanges average coefficient of 0.30 (again based on the values in Table 5). That is, for both risky asset-class net exchanges and safe asset-class net exchanges, we see approximately double the proportional movement in Canada that we see in the United States, on average. Of course, the dollar magnitudes of both these exchanges are much larger for U.S. funds due to the size of the U.S. market. The remaining coefficient estimates are similar to what we have seen earlier; there is strong evidence of autocorrelation, return chasing, and some impact consistent with the avoidance of funds that have experienced recent capital gains.

In Panel B of Table 5, we present statistics testing the joint significance of the onset/recovery coefficient estimates and testing model fit. These tests provide strong evidence of a seasonal pattern in fund exchanges consistent with seasonally varying risk aversion influencing asset-allocation decisions, and the goodness-offit test indicates that the overidentifying moment restrictions we use to estimate the model are not rejected.

In Figure 6, we summarize the average dollar impact on net exchanges associated with onset/recovery for Canadian funds, for $2006 .{ }^{38}$ Each line represents, for a given asset class, the average monthly economic magnitude of the effect we

\section{FIGURE 6}

\section{Canadian Net Exchanges Attributed to Seasonally Varying Risk}

Figure 6 reports the monthly net exchanges due to seasonally varying risk aversion, in billions of Canadian dollars, for equity, hybrid, fixed-income, and global fixed-income funds, for 2006, predicted from equation (3) as arising from onset/recovery.

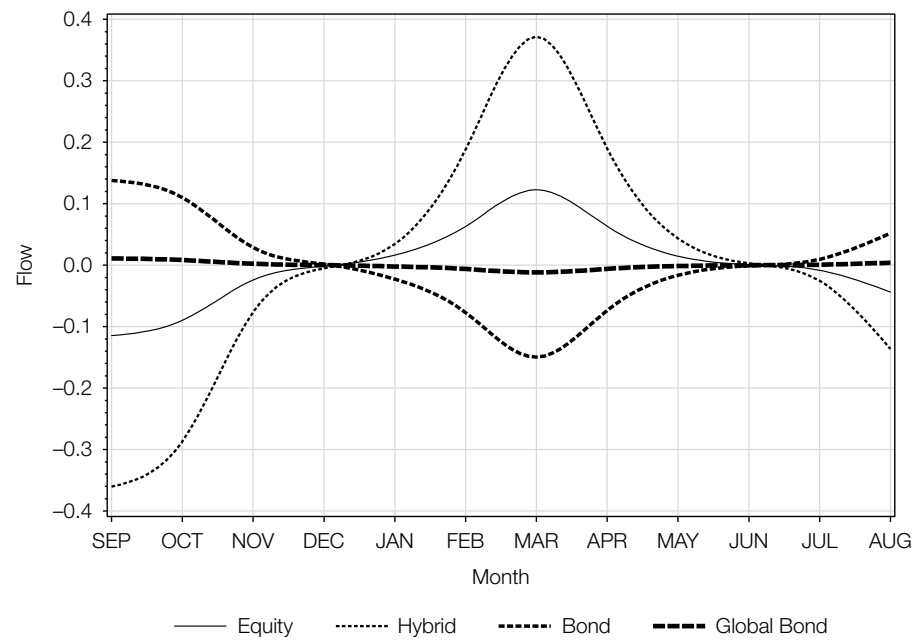

\footnotetext{
${ }^{38}$ To estimate the total monthly impact in the setting of a model with autoregressive terms, we divide the immediate impact by 1 minus the sum of the autoregressive coefficients. This is identical to the process used for the United States.
} 
attribute to seasonally varying risk aversion. The thin solid line corresponds to equities, the thin dashed line that varies most corresponds to the hybrid class, the dashed line that moves the most in an opposing fashion relative to the equity and hybrid classes is the fixed-income category (labeled "bond"), and the thick dashed line that varies least is the global fixed-income category (labeled "global bond"). We see that both bond asset classes display opposing movements relative to the equity and hybrid asset classes. The annual variation in net exchanges due to onset/recovery for Canadian hybrid and equity classes peaks around plus or minus 0.5 billion Canadian dollars (CAD) in total. ${ }^{39}$ The domestic fixed-income asset class in Canada varies by roughly plus or minus 0.14 billion CAD, and the global fixed-income asset class varies minimally. ${ }^{40}$ The Canadian net exchanges are relatively large compared to those of the United States when considering the economy of the United States is roughly 11 times larger than Canada's. For comparison, the U.S. equity net exchanges oscillate at approximately plus or minus $\$ 3.5$ billion over the seasons, circa 2006, roughly $15 \%$ less proportionally than Canada after accounting for the exchange rate, and the U.S. money market and government bond fund classes vary seasonally by roughly plus or minus a half billion dollars, less than $1 / 10$ the variation we see in the safe asset classes in Canada. The relatively larger economic impact on Canadian versus U.S. net exchanges aligns with the relatively larger Canadian versus U.S. coefficient estimates discussed previously.

\section{B. Australian Flows}

Next, we test whether the relation of mutual fund flows to the seasonal onset/recovery pattern is similar in a developed market in the southern hemisphere, where the relation between the calendar and the seasons is offset by 6 months relative to North America. This helps us to identify the seasonally varying riskaversion effect on flows independent of the actual calendar month. Specifically, we examine net flows to/from Australian-domiciled equity funds that invest in Australian equities, with the assumption that the majority of flows for these funds come from individuals in Australia.

We obtain end-of-month TNA from Morningstar for all Australian-domiciled mutual funds with an Australian equity focus for the period Jan. 1991Dec. 2007. ${ }^{41,42}$ We estimate monthly net flows for each fund as the fractional change in total net assets, minus the investment return of the fund; flows are then aggregated across all equity funds. The need for lagged values restricts the range of data we use in the regression model to start in Jan. 1992, and we again end the sample in Dec. 2006. Unfortunately, Australian net exchange data are not available, and we are not able to obtain data on Australian government money market funds, so we proceed with an analysis that focuses solely on equity fund net flows. To minimize the influence of any potential data errors or outliers, we eliminate all

\footnotetext{
${ }^{39}$ Exchange rates circa 2006 placed a $10 \%-15 \%$ premium on the U.S. dollar.

${ }^{40}$ Untabulated robustness checks exploiting the moment condition that the net exchanges sum to 0 do not result in qualitative changes in the results.

${ }^{41}$ Although earlier data are available, the number of funds in the database is well below 100 prior to 1991 .

${ }^{42}$ The Morningstar equity categories include Large Blend, Large Geared (leveraged), Large Growth, Large Value, Mid/Small Blend, Mid/Small Growth, Mid/Small Value, and Other (natural resources, ethical, quant, etc.).
} 
fund-month observations having an inflow or outflow greater (in absolute value) than $10 \%$ of the prior month-end TNA. ${ }^{43}$ Our sample consists of 91 funds with a total market value of 1.6 billion Australian dollars (AUD) on Jan. 1, 1991 (equivalent to roughly 1.2 billion USD at that date), growing to 599 funds with a total market value of 70.2 billion AUD by Dec. 31, 2006 (approximately 55.3 billion USD at that date). This market is roughly $1 \%$ of the size (in value) of the U.S. equity mutual fund market as of Dec. 31, 2006. In Internet Appendix Section A-8, we report summary statistics and plots based on the Australian net flows.

Next, we turn to a conditional analysis of the Australian data, estimating the following regression model:

$$
\begin{aligned}
& \mathrm{NET} \_F L O W_{i, t}=\mu_{i}+\mu_{i, \hat{\mathrm{OR}}_{\mathrm{SOUTH}}} \hat{\mathrm{OR}}_{\mathrm{SOUTH}_{t}}+\mu_{i, R} \mathrm{YEAR} R_{i, t}^{\mathrm{YEAR}}
\end{aligned}
$$

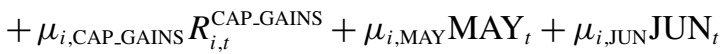

$$
\begin{aligned}
& +\mu_{i, \mathrm{JUL}} \mathrm{JUL}_{t}+\mu_{i, \mathrm{AUG}} \mathrm{AUG}_{t}+\rho_{i, 1} \mathrm{NET} \_\mathrm{FLOW}_{i, t-1} \\
& +\rho_{i, 2} \text { NET_FLOW }{ }_{i, t-2}+\rho_{i, 3} \text { NET_FLOW }_{i, t-3}+\epsilon_{i, t} \text {, }
\end{aligned}
$$

where $i$ references the equity mutual fund asset class. The dependent variable, NET_FLOW $_{i, t}$, is the month $t$ aggregate fund flow expressed as a percentage of month $t-1$ total net assets. $\hat{\mathrm{OR}}_{\mathrm{SOUTH}_{t}}$ is the onset/recovery variable offset by 6 months from its U.S. counterpart to align with the southern hemisphere seasons, ${ }^{44}$ and $R_{i, t}^{\mathrm{YEAR}}$ is the return to the equity fund asset class over the prior 12 months (i.e., from month $t-13$ through month $t-1$ ), included to control for return-chasing flows. $R_{i, t}^{\text {CAP_GAINS }}$, which is included to control for the influence of capital-gains overhang on flows, equals the cumulated return to holding the fund from the previous July 1 (the start of the tax year in Australia) until month $t-1$ (hence $R_{i, t}^{\text {CAP_GAINS }}$ equals 0 for July by construction). MAY $, \mathrm{JUN}_{t}, \mathrm{JUL}_{t}$, and $\mathrm{AUG}_{t}$ are dummy variables for monthly flows, taking on values of 1 in the indicated month, and 0 otherwise. We include dummy variables for the months around the tax year because net flows are likely perturbed by turn-of-year tax effects, much as they are in the United States and Canada. In robustness checks provided in Internet Appendix Section A-8, we demonstrate that the findings are not driven by inclusion/exclusion of these dummy variables. In an untabulated analysis, we additionally find that the Australian results are qualitatively invariant to how we control for autocorrelation. We are not able to obtain Australian savings-rate or mutual-fund-family advertising data.

Table 6 contains estimation results for equation (4). The model, although more parsimonious than that estimated for U.S. flows, still explains much of the

\footnotetext{
${ }^{43}$ There are occasional missing TNA observations for individual funds in the Australian data. Because TNA is used to form the inferred asset-class flows, a missing value for a large fund can artificially reduce estimates of asset-class TNA for a given month, which in turn can lead to a large estimated outflow for that month followed by a large estimated inflow. Filtering the data by eliminating flows greater than $10 \%$ (in absolute value) minimizes the impact of these errors. Such data points are rare, constituting only $0.15 \%$ of the sample of fund-months.

${ }^{44} \mathrm{We}$ are not aware of any studies that provide estimates of weekly or monthly onset/recovery figures for seasonal depression in Australia's population. Because daylight in the southern hemispheres follows a sine wave shifted by 6 months relative to the northern hemisphere, we use the northern hemisphere's $\hat{\mathrm{OR}}_{t}$ variable shifted by 6 months as a best-available approximation for the timing of onset and recovery in the southern hemisphere.
} 
TABLE 6

Regression Results for Australian Equity Fund Net Flows

In Table 6, we report coefficient estimates from estimating the following regression with GMM using Australian data:

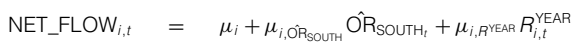

$$
\begin{aligned}
& +\mu_{i, \text { CAP_GAINS }} R_{i, t}^{\text {CAP_GAINS }}+\mu_{i, \mathrm{MAYMAY}_{t}}+\mu_{i, \mathrm{JUN}} \mathrm{JUN}_{t} \\
& +\mu_{i, \mathrm{JUL}} \mathrm{JUL}_{t}+\mu_{i, \mathrm{AUG}} \mathrm{AUG}_{t}+\rho_{i, 1} \mathrm{NET} \mathrm{FLOW}_{i, t-1} \\
& +\rho_{i, 2} \text { NET_FLOW }_{i, t-2}+\rho_{i, 3} \text { NET_FLOW }_{i, t-3}+\epsilon_{i, t} \text {. }
\end{aligned}
$$

The data used to estimate the model span Jan. 1992 through Dec. 2006. The monthly net flows are estimated as the fraction change in total net assets minus the investment return of the fund; flows are then aggregated across all equity funds. The explanatory variables are defined in the text. We present coefficient estimates with HAC robust $t$-tests (reported in parentheses) and the value of adjusted $R^{2}$, a Wald $\chi^{2}$ test statistic for the presence of up to 12 lags of autocorrelation $(A R)$, and a Wald $\chi^{2}$ test statistic for the presence of up to 12 lags of ARCH (both with 12 degrees of freedom). The test for ARCH is a standard LM test of order 12. See Engle (1982). To perform the test for autocorrelation, we augment the regression with 12 lags of the residuals, estimate MacKinnon and White (1985) bootstrap heteroskedasticity-consistent standard errors with OLS, and test for the joint significance of these terms. For this case, we have no panel with joint tests. We have only one series, so the joint tests on onset/recovery are redundant. The Hansen (1982) $\chi^{2}$ goodness-of-fit joint test of the model is not valid because we have an exactly identified system. To calculate the standard errors, we follow Newey and West (1987), (1994) and use the Bartlett kernel and an automatic bandwidth parameter (autocovariance lags)

\begin{tabular}{|c|c|}
\hline $\begin{array}{l}\text { Parameter } \\
\text { or Statistic } \\
\end{array}$ & $\begin{array}{c}\text { Australian } \\
\text { Equity } \\
\end{array}$ \\
\hline$\mu$ & $\begin{array}{l}-0.029 \\
(-0.64)\end{array}$ \\
\hline$\mu_{\text {ORSOUTH }}$ & $\begin{array}{l}-0.359^{\star \star} \\
(-2.39)\end{array}$ \\
\hline$\mu_{R_{\text {YEAR }}}$ & $\begin{array}{c}0.054 \\
(1.07)\end{array}$ \\
\hline$\mu_{\text {CAP_GAINS }}$ & $\begin{array}{c}0.003 \\
(0.50)\end{array}$ \\
\hline$\mu_{\mathrm{MAY}}$ & $\begin{array}{l}0.217^{* \star} \\
(2.17)\end{array}$ \\
\hline$\mu_{\mathrm{JUN}}$ & $\begin{array}{l}-0.159 \\
(-1.09)\end{array}$ \\
\hline$\mu_{\mathrm{JUL}}$ & $\begin{array}{l}-0.220 \\
(-1.35)\end{array}$ \\
\hline$\mu_{\mathrm{AUG}}$ & $\begin{array}{l}0.287^{\text {** }} \\
(2.59)\end{array}$ \\
\hline$\rho_{1}$ & $\begin{array}{l}0.219^{\text {** }} \\
(3.90)\end{array}$ \\
\hline$\rho_{2}$ & $\begin{array}{l}0.383^{\star \star \star} \\
(5.29)\end{array}$ \\
\hline$\rho_{3}$ & $\begin{array}{l}0.251^{\text {*** }} \\
(3.72)\end{array}$ \\
\hline $\begin{array}{l}R^{2} \\
\mathrm{AR}(12) \\
\mathrm{ARCH}(12)\end{array}$ & $\begin{array}{c}0.592 \\
14.78 \\
10.67\end{array}$ \\
\hline
\end{tabular}
equal to the integer value of $4(T / 100)^{2 / 9}$. We use the full set of explanatory variables as instruments for the regression. *, **, and *** indicate significance at the $10 \%, 5 \%$, and $1 \%$ levels, respectively, based on 2 -sided tests.

variation in Australian flows, with an $R^{2}$ above $60 \%$. The residuals show no statistically significant evidence of autocorrelation or ARCH effects, and similar to the U.S. case, unadjusted Australian equity monthly net flows show strong positive autocorrelation. As with U.S. equities, the sign of the onset/recovery variable is significantly negative (recall that we use a southern hemisphere version of the onset/recovery variable, and thus we expect to find the same sign for equity funds in Australia as we see for equity funds in the northern hemisphere countries). Further, the magnitude is economically meaningful and similar to the findings for U.S. funds: The coefficient value of -0.359 corresponds to a 35.9-bps impact per unit of the onset/recovery variable, and onset/recovery varies between roughly 
plus and minus .4. This translates into approximately 14 bps of seasonal variation in flows in either direction associated with seasonal depression. We find little evidence of return chasing or from capital gains.

In Figure 7, we summarize the average economic impact associated with seasonally varying risk aversion for Australian equity funds, for 2006, with the thin line representing flows due to onset/recovery. ${ }^{45}$ Naturally, the flows are much smaller in magnitude than the corresponding flows for the United States, varying between maximum outflows and inflows of approximately 0.4 billion AUD (roughly 0.3 billion USD in 2006). Because the U.S. economy is roughly 15 times larger than Australia's, the size-adjusted equity flows for Australia are less than half of those of U.S. flows, which are close to 15 billion USD for the equity class alone.

FIGURE 7

Australian Net Flows Attributed to Seasonally Varying Risk

In Figure 7, we report the monthly net flows due to onset/recovery, in billions of AUD, for equity funds, for 2006. The data on equity fund flows, provided by Morningstar, span Jan. 1, 1991 through Dec. 31, 2007.

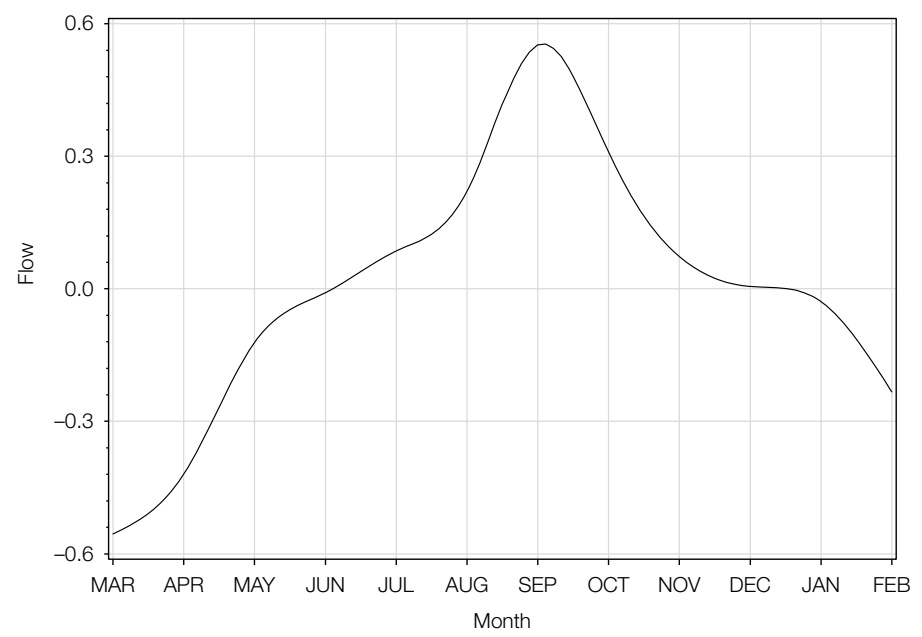

\section{Robustness of Results}

First, in a previous version of this paper, we used returns and TNA from the CRSP Mutual Fund Database to produce flows for risky and safe categories of mutual funds. Results are qualitatively identical to those we report here based on the ICI data. Second, we find virtually identical results for the United States when we exclude the first few years or the first half of the sample. Third, the ICI implemented changes in its data-collection practices in Jan. 1990,

\footnotetext{
${ }^{45}$ To estimate the monthly impact based on a model with autoregressive terms, we divide the immediate impact by 1 minus the sum of the autoregressive coefficients. This is identical to the process used for the United States and Canada.
} 
an artifact of which is outliers in the flow and returns data in that year. As a result, we explore omitting 1990 from the sample, which produces no qualitative changes in the results. Fourth, in the main analysis, we end the U.S., Canadian, and Australian samples uniformly in Dec. 2006 to avoid possible contamination from the financial crisis. In robustness checks, we extend the sample end points to include the most recent set of data available. Our findings with respect to the influence of onset/recovery on flows are qualitatively unchanged. Fifth, we reestimate the models while imposing a moment condition on flows due to onset/recovery (and exchanges due to onset/recovery) so that the total impact from onset/recovery will net out to 0 . This tightens standard errors but does not produce other notable changes in the estimation. Sixth, we include a dummy variable in the model to allow a reversal of flows from December to January for the United States and Canada (from June to July for Australia) related to tax-year rebalancing and a dummy variable to allow a reversal of flows from October to November for the United States. These produce no qualitative change in the seasonally varying risk-aversion results. Seventh, we use seemingly unrelated regression methods to estimate the system of equations, with MacKinnon and White (1985) bootstrap heteroskedasticity-robust standard errors and sufficient lags to control for autocorrelation. This approach yields similar results to GMM for both magnitude of the seasonally varying risk-aversion effect and significance of the joint effect, although individual onset/recovery coefficients are less statistically significant.

Eighth, we explore alternate proxies for capturing return-chasing behavior, using the prior 1 month, 1 quarter, 2 quarters, or 3 quarters of returns instead of the past year. As shown in Internet Appendix Section A-1, these model permutations produce no qualitative differences in the core result. Ninth, when we use the change in the length of night rather than onset/recovery, we find qualitatively identical results. These results also appear in Internet Appendix Section A-1. Tenth, we find that excluding turn-of-tax-year dummies (November, December, January, and February for the United States and Canada, and May, June, July, and August for Australia) leads to no marked changes in the results; see Internet Appendix Section A-1. Eleventh, in Internet Appendix Section A-4, we show that the U.S. results are robust to a less coarse classification of the ICI categories into nine asset classes rather than five (and in untabulated results, we find that the results are robust to use of the full set of 33 categories provided by the ICI). Results based on Canadian data are similarly robust to more granular classification into 10 asset classes, as shown in Internet Appendix Section A-7. Twelfth, in Internet Appendix Section A-6 we show that the U.S. results are robust to inclusion/exclusion of lags of the dependent variable (as are the Canadian and Australian results, based on an untabulated analysis). Thirteenth, in Internet Appendix Section A-3, we perform our analysis using net flows and net exchanges associated with retail share classes only, omitting data associated with "institutional" share classes (some of which are populated with individual investors collected together as a group, e.g., a $401(\mathrm{k})$ plan). Our findings are qualitatively unchanged relative to analysis on the full set of data.

Fourteenth, in Internet Appendix Section A-9, we explore whether the observed seasonality in flows is driven by differences across periods with high versus 
low equity market returns, capital gains, mutual fund sales, or redemptions. For instance, if investors exhibit flight-to-liquidity behavior during market crashes, then the fact that market crashes occur with more frequency in the fall may mechanically lead to the observed seasonal flows into and out of safe versus risky mutual funds. We consistently find above-average money market flows in the summer/fall and below-average money market flows in the winter/spring, and the reverse for equity fund flows, regardless of how we condition the data. That is, the seasonal flows pattern is consistent with seasonally varying investor risk aversion during high and low periods of contemporaneous equity returns, capital gains, sales, and redemptions.

Finally, we explore extensive variations in the way we capture capital-gains overhang, detailed in Internet Appendix Section A-1, for net flows and net exchanges, each using 10 alternative measures of overhang. These robustness checks demonstrate that the findings do not hinge on the way we measure capital gains. Please see the Internet Appendix for the extended discussion of these constructions and results.

\section{Conclusion}

We document a seasonal pattern in mutual fund flows that is consistent with individual investors becoming more risk averse in the fall, as days shorten, and less risk averse in the winter/spring, as days lengthen, that is, consistent with individuals experiencing changes in sentiment due to seasonal depression. SAD is a seasonal form of depression that affects between $1 \%$ and $10 \%$ of the population severely (depending on location and the diagnostic criteria used to test for seasonal depression) and much of the rest of the population subclinically, with those affected experiencing depression and risk aversion that increase with the length of night. Although prior studies have found economically and statistically significant evidence of a systematic influence of seasonal depression on stock and Treasury bond returns, this study is the first to directly link seasonal cycles in household sentiment toward risk taking with seasonal patterns in directly measured investment quantities.

Specifically, we find that net flows and net exchanges (a measure of investor sentiment studied by Ben-Rephael et al. (2011), (2012)) for the riskiest group of mutual funds, equities, are lower in the fall and higher in the spring, whereas flows for the safest category, money market funds, exhibit the opposite pattern. We find that these seasonal patterns are significantly related to onset/recovery after controlling for other known influences on flows/exchanges, including past returns, advertising, and capital-gains distributions. Further, the significant explanatory power of the onset/recovery variable is robust to inclusion/exclusion of sufficient lags of the dependent variable to control for autocorrelation, indicating that the onset/recovery variable is not picking up simple lead-lag effects in unexpected flows. The evidence for mood-related seasonality survives subsample analysis, finer granularity of analysis of fund class, alternate measures of capital-gains overhang and return chasing, various other model refinements, and the study of international fund data, including Canada (a more northerly country where flows exhibit stronger seasonal variation, consistent with the greater prevalence 
of seasonal depression documented in Canada) and Australia (a southern hemisphere country where the seasons and seasonal flow pattern are 6 months offset relative to the United States).

The seasonal flows associated with seasonally varying investor risk aversion are economically large, representing tens of billions of dollars. These large flows are consistent with the seasonal effects in stock and bond returns documented by Kamstra et al. (2003), (2015) and Garrett et al. (2005). They are also consistent with the general equilibrium asset pricing model explored by Kamstra et al. (2014), in which the representative agent exhibits seasonally varying risk aversion and intertemporal elasticity of substitution. Further research is needed to investigate whether trades by fund managers due to these investor flows impact stock and bond returns. In addition, future research might investigate the trading behavior of individuals, using brokerage data sets, to study seasonality in household behavior on a microlevel.

Finally, it is noteworthy that the mutual fund industry spends more than half a billion dollars per year on advertising. Our findings suggest that businesses in this industry might be well advised to time their promotion efforts to the seasons. The most fruitful ad campaign may be one that aggressively pushes safe classes of funds in the fall, when many individual investors are more risk averse than usual, and then promotes riskier funds through the winter and into spring, when risk aversion is reverting to "normal" levels. Of course, as the seasons continue their cycle independently of financial markets, no level of risk aversion should occupy a favored "normal" status. This is an important implication for any research where outcomes are sensitive to the specific assumptions made about risk aversion.

\section{References}

Aydogdu, M., and J. W. Wellman. "The Effects of Advertising on Fund Flows: Results from a New Database." Financial Management, 40 (2011), 785-809.

Bassi, A.; R. Colacito; and P. Fulghieri. "'O Sole Mio: An Experimental Analysis of Weather and Risk Attitudes in Financial Decisions.” Review of Financial Studies, 26 (2013), 1824-1852.

Ben-Rephael, A.; S. Kandel; and A. Wohl. "The Price Pressure of Aggregate Mutual Fund Flows." Journal of Financial and Quantitative Analysis, 46 (2011), 585-603.

Ben-Rephael, A.; S. Kandel; and A. Wohl. "Measuring Investor Sentiment with Mutual Fund Flows." Journal of Financial Economics, 104 (2012), 363-382.

Bergstresser, D., and J. Poterba. "Do After-Tax Returns Affect Mutual Fund Inflows?” Journal of Financial Economics, 63 (2002), 381-414.

Carton, S.; R. Jouvent; C. Bungenera; and D. Widlöcher. "Sensation Seeking and Depressive Mood." Personality and Individual Differences, 13 (1992), 843-849.

Carton, S.; P. Morand; C. Bungenera; and R. Jouvent. "Sensation-Seeking and Emotional Disturbances in Depression: Relationships and Evolution." Journal of Affective Disorders, 13 (1995), 219-225.

Eisenberg, A. E.; J. Baron; and M. E. P. Seligman. "Individual Differences in Risk Aversion and Anxiety." Working Paper, University of Pennsylvania (1998).

Engle, R. F. "Autoregressive Conditional Heteroskedasticity with Estimates of the Variance of UK Inflation.” Econometrica, 50 (1982), 987-1008.

Gallaher, S.; R. Kaniel; and L. Starks. "Mutual Funds and Advertising." Working Paper, University of Texas at Austin (2006).

Garrett, I.; M. J. Kamstra; and L. A. Kramer. "Winter Blues and Time Variation in the Price of Risk." Journal of Empirical Finance, 12 (2005), 291-316.

Guiso, L.; P. Sapienza; and L. Zingales. "Time Varying Risk Aversion.” Working Paper, University of Chicago (2013).

Hansen, L. P. "Large Sample Properties of Generalized Method of Moments Estimators." Econometrica, 50 (1982), 1029-1084. 
Harlow, W. V., and K. C. Brown. "Understanding and Assessing Financial Risk Tolerance: A Biological Perspective." Financial Analysts Journal, 6 (1990), 50-80.

Harmatz, M. G.; A. D. Well; C. E. Overtree; K. Y. Kawamura; M. Rosal; and I. S. Ockene. "Seasonal Variation of Depression and Other Moods: A Longitudinal Approach.” Journal of Biological Rhythms, 15 (2000), 344-350.

Hirshleifer, D., and T. Shumway. "Good Day Sunshine: Stock Returns and the Weather." Journal of Finance, 58 (2003), 1009-1032.

Horvath, P., and M. Zuckerman. "Sensation Seeking, Risk Appraisal, and Risky Behavior.” Personality and Individual Differences, 14 (1993), 41-52.

Indro, D. C. "Does Mutual Fund Flow Reflect Investor Sentiment?" Journal of Behavioral Finance, 5 (2004), 105-115.

Investment Company Institute. Mutual Fund Fact Book: A Guide to Trends and Statistics in the Mutual Fund Industry, 43rd ed. Washington, DC: Investment Company Institute (2003).

Investment Company Institute. Mutual Fund Fact Book: A Review of Trends and Activity in the Investment Company Industry, 54th ed. Washington, DC: Investment Company Institute (2014).

Ippolito, R. A. "Consumer Reaction to Measures of Poor Quality: Evidence from the Mutual Fund Industry." Journal of Law and Economics, 35 (1992), 45-70.

Jain, P. C., and J. S. Wu. "Truth in Mutual Fund Advertising: Evidence on Future Performance and Fund Flows.” Journal of Finance, 55 (2000), 937-958.

Johnson, W. T., and J. M. Poterba. "Taxes and Mutual Fund Inflows around Distribution Dates.” NBER Working Paper 13884 (2008).

Kamstra, M. J.; L. A. Kramer; and M. D. Levi. "Winter Blues: A SAD Stock Market Cycle.” American Economic Review, 93 (2003), 324-343.

Kamstra, M. J.; L. A. Kramer; and M. D. Levi. "A Careful Re-Examination of Seasonality in International Stock Markets: Comment on Sentiment and Stock Returns." Journal of Banking and Finance, 36 (2012), 934-956.

Kamstra, M. J.; L. A. Kramer; and M. D. Levi. "Seasonal Variation in Treasury Returns." Critical Finance Review, 4 (2015), 45-115.

Kamstra, M. J.; L. A. Kramer; M. D. Levi; and T. Wang. "Seasonally Varying Preferences: Theoretical Foundations for an Empirical Regularity." Review of Asset Pricing Studies, 4 (2014), 39-77.

Karceski, J. "Returns-Chasing Behavior, Mutual Funds, and Beta's Death.” Journal of Financial and Quantitative Analysis, 37 (2002), 559-594.

Kasper, S.; T. A. Wehr; J. J. Bartko; P. A. Gaist; and N. E. Rosenthal. "Epidemiological Findings of Seasonal Change in Mood and Behavior: A Telephone Survey of Montgomery County, Maryland." Archives of General Psychiatry, 46 (1989), 823-833.

Kramer, L. A., and J. M. Weber. "This Is Your Portfolio on Winter: Seasonal Affective Disorder and Risk Aversion in Financial Decision-Making." Social Psychological and Personality Science, 3 (2012), 193-199.

Kumler, M. P., and M. F. Goodchild. "The Population Center of Canada-Just North of Toronto?” In Geographical Snapshots of North America. New York, NY: Guilford (1992), 275-279.

Lam, R. W. (ed.). Seasonal Affective Disorder and Beyond: Light Treatment for SAD and Non-SAD Conditions. Washington, DC: American Psychiatric Press (1998a).

Lam, R. W. (ed.). "Seasonal Affective Disorder: Diagnosis and Management." Primary Care Psychiatry, 4 (1998b), 63-74.

Levi, M. D. "Errors in the Variables Bias in the Presence of Correctly Measured Variables." Econometrica, 41 (1973), 985-986.

MacKinnon, J. G., and H. White. "Some Heteroskedasticity-Consistent Covariance Matrix Estimators with Improved Finite Sample Properties.” Journal of Econometrics, 29 (1985), 305-325.

Magnusson, A. "An Overview of Epidemiological Studies on Seasonal Affective Disorder." Acta Psychiatrica Scandinavica, 101 (2000), 176-184.

Malmendier, U., and S. Nagel. "Depression Babies: Do Macroeconomic Experiences Affect Risk Taking?" Quarterly Journal of Economics, 126 (2011), 373-416.

Mersch, P. "Prevalence from Population Surveys." In Seasonal Affective Disorder: Practice and Research, T. Partonen and A. Magnusson, eds. Oxford, UK: Oxford University Press (2001).

Molin, J.; E. Mellerup; T. Bolwig; T. Scheike; and H. Dam. "The Influence of Climate on Development of Winter Depression.” Journal of Affective Disorders, 37 (1996), 151-155.

Newey, W. K., and K. D. West. "A Simple, Positive, Semi-Definite, Heteroskedasticity and Autocorrelation Consistent Covariance Matrix.” Econometrica, 55 (1987), 703-708.

Newey, W. K., and K. D. West. "Automatic Lag Selection in Covariance Matrix Estimation.” Review of Economic Studies, 61 (1994), 631-653.

Pietromonaco, P. R., and K. S. Rook. "Decision Style in Depression: The Contribution of Perceived Risks versus Benefits.” Journal of Personality and Social Psychology, 52 (1987), 399-408. 
Remolona, E. M.; P. Kleiman; and D. Gruenstein. "Market Returns and Mutual Fund Flows." Federal Reserve Bank of New York's Economic Policy Review, (1997), 33-52.

Reuter, J., and E. W. Zitzewitz. "Do Ads Influence Editors? Advertising and Bias in the Financial Media." Quarterly Journal of Economics, 121 (2006), 197-227.

Rosen, L. N.; S. D. Targum; M. Terman; M. J. Bryant; H. Hoffman; S. F. Kasper; J. R. Hamovit; J. P. Docherty; B. Welch; and N. E. Rosenthal. "Prevalence of Seasonal Affective Disorder at Four Latitudes." Psychiatry Research, 31 (1990), 131-144.

Rosenthal, N. E. Winter Blues, Revised Edition: Everything You Need to Know to Beat Seasonal Affective Disorder. New York, NY: Guilford Press (2006).

Rosenthal, N. E.; D. A. Sack; J. C. Gillin; A. J. Lewy; F. K. Goodwin; Y. Davenport; P. S. Mueller; D. A. Newsome; and T. A. Wehr. "Seasonal Affective Disorder: A Description of the Syndrome and Preliminary Findings with Light Therapy." Archives of General Psychiatry, 41 (1984), 72-80.

Schmidt, L.; A. Timmermann; and R. Wermers. "Runs on Money Market Mutual Funds." American Economic Review, 106 (2016), 2625-2657.

Sciortino, J. J.; J. H. Huston; and R. W. Spencer. "Perceived Risk and the Precautionary Demand for Money." Journal of Economic Psychology, 8 (1987), 339-346.

Sialm, C.; L. T. Starks; and H. Zhang. "Defined Contribution Pension Plans: Sticky or Discerning Money?" Journal of Finance, 70 (2015), 805-838.

Sirri, E. R., and P. Tufano. "Costly Search and Mutual Fund Flows." Journal of Finance, 53 (1998), 1589-1622.

Smoski, M. J.; T. R. Lynch; M. Z. Rosenthal; J. S. Cheavens; A. L. Chapman; and R. R. Krishnan. "Decision-Making and Risk Aversion among Depressive Adults." Journal of Behavior Therapy, 39 (2008), 567-576.

Terman, M. "On the Question of Mechanism in Phototherapy: Considerations of Clinical Efficacy and Epidemiology.” Journal of Biological Rhythms, 3 (1988), 155-172.

Thompson, C.; S. Thompson; and R. Smith. "Prevalence of Seasonal Affective Disorder in Primary Care: A Comparison of the Seasonal Health Questionnaire and the Seasonal Pattern Assessment Questionnaire." Journal of Affective Disorders, 78 (2004), 219-226.

Warther, V. A. "Aggregate Mutual Fund Flows and Security Returns." Journal of Financial Economics, 39 (1995), 209-235.

Wong, A., and B. Carducci. "Sensation Seeking and Financial Risk Taking in Everyday Money Matters." Journal of Business and Psychology, 5 (1991), 525-530.

Young, M. A.; P. M. Meaden; L. F. Fogg; E. A. Cherin; and C. I. Eastman. "Which Environmental Variables Are Related to the Onset of Seasonal Affective Disorder?" Journal of Abnormal Psychology, 106 (1997), 554-562.

Zuckerman, M. Biological Bases of Sensation Seeking, Impulsivity and Anxiety. Hillsdale, NJ: Lawrence Erlbaum Associates, Inc. (1983).

Zuckerman, M. Behavioral Expressions and Biosocial Bases of Sensation Seeking. New York, NY: Cambridge University Press (1994). 